\title{
Using Smart Card Technology to Prevent Sales of Alcohol to Underage Persons
}


This publication is distributed by the U.S. Department of Transportation, National Highway Traffic Safety Administration, in the interest of information exchange. The opinions, findings and conclusions expressed in this publication are those of the author(s) and not necessarily those of the Department of Transportation or the National Highway Traffic Safety Administration. The United States Government assumes no liability for its content or use thereof. If trade or manufacturer's names or products are mentioned, it is because they are considered essential to the object of the publication and should not be construed as an endorsement. The United States Government does not endorse products or manufacturers. 
Technical Report Documentation Page

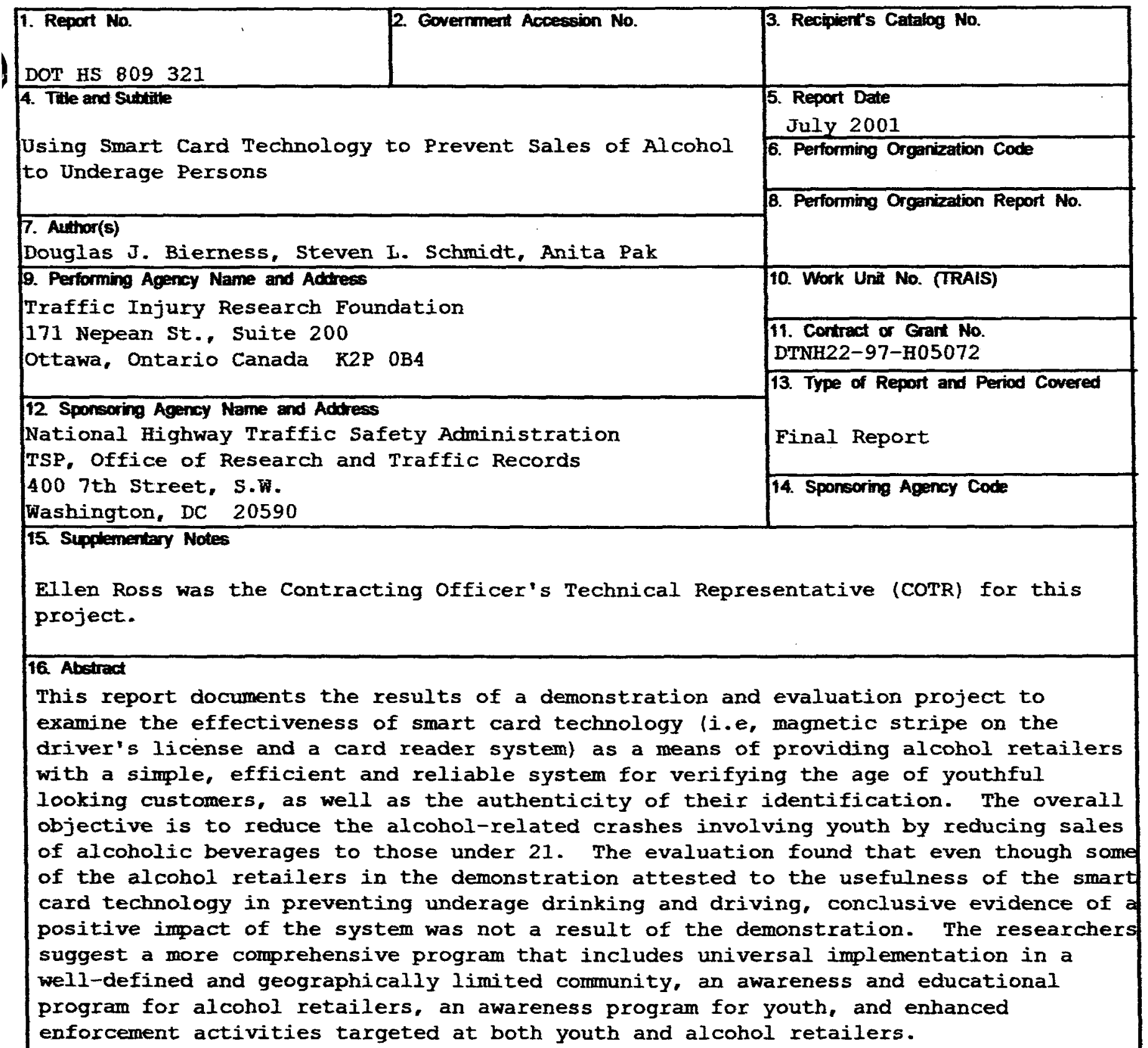

\section{Key Words}

Underage drinking, Minor checker program, DuI, traffic crashes, education/awareness campaigns, card reader, compliance checks, alcohol retailers, youth

19. Sectrity Chassit. (of this report)

\section{Distribution Statement}

This report is available from CONWAL, 3341

75th Ave., Ste. F, Landover, MD 20785

(301) 386-4789, or at

www - nhtsa . dot . gov/people/Injury/al cohol/yo 


\section{TABLE OF CONTENTS}

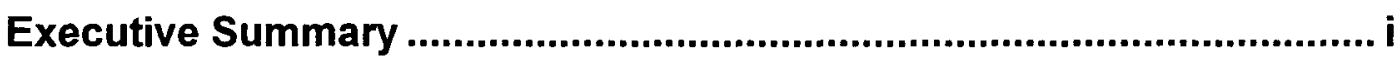

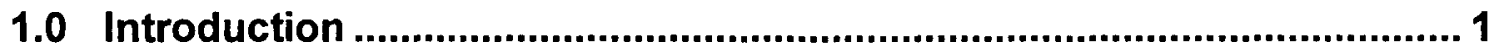

1.1 Background 1

1.2 Access to Alcohol 2

1.3 Responsibility of Licensed Retailers 4

1.4 An Innovative Approach: Using Smart Card Technology 6

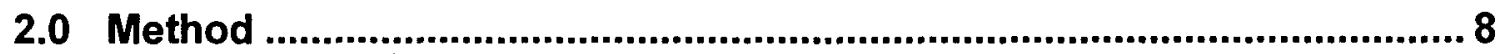

2.1 Overview 8

2.2 Background $\quad$. 8

2.3 Implementation 9

2.4 Youth Awareness Program 10

2.5 Discussion 10

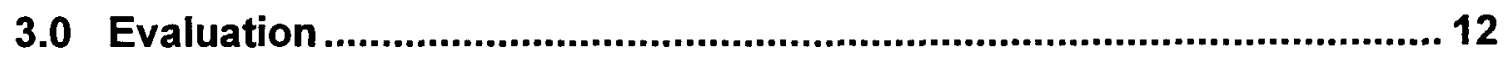

3.1 Overview 12

3.2 Process Evaluation 12

3.2.1 Focus groups 12

$\begin{array}{ll}3.2 .2 \text { Licensee interviews } & 20\end{array}$

$\begin{array}{ll}3.2 .3 \text { MinorChecker }^{\circledR} \text { records } & 22\end{array}$

$\begin{array}{ll}3.2 .4 \text { Discussion } & 27\end{array}$

$\begin{array}{ll}3.3 \text { Outcome Evaluation } & 27\end{array}$

$\begin{array}{ll}\text { 3.3.1 Compliance check } & 27\end{array}$

3.3.2 Alcohol-related offenses $\quad 31$

3.3.3 Alcohol-related traffic crashes $\quad 35$

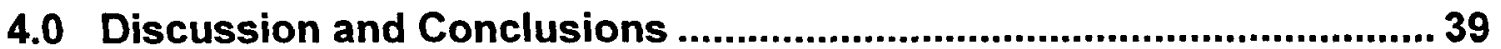

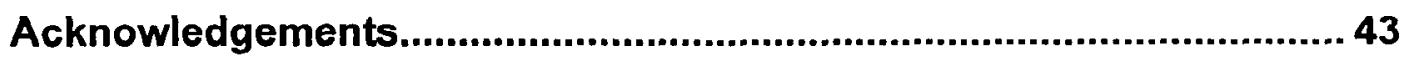

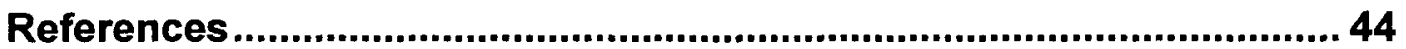

Appendix A: Declaration of Age Form (PLCB-931) .............................. 47 


\section{EXECUTIVE SUMMARY}

In an effort to reduce sales of alcoholic beverages to persons under age 21, the Pennsylvania Liquor Control Board (PLCB) enlisted CommStar Inc. to develop the hardware and software for a simple, efficient and reliable system for verifying the age of a customer as well as the authenticity of the identification. The system - called the Minor Checker - provides retailers and servers of alcohol with the ability to quickly and easily determine the age of a potential customer as well as the authenticity of the identification by simply swiping the driver's license through a card reader. Providing retailers and servers of alcohol with an easy-to-use, reliable and objective means of determining a person's age has the potential to have a significant impact on sales of alcohol to minors and problems associated with underage drinking, including driving after drinking.

The purpose of this project was to evaluate the utility and effectiveness of the MinorChecker ${ }^{\otimes}$ system. MinorChecker ${ }^{\oplus}$ units were provided to 60 licensed alcohol outlets in the city of York, Pennsylvania. An education/awareness campaign on underage drinking directed at both licensees and youth complemented the introduction of the card readers. A second community (Williamsport) was targeted with the same education/awareness program but no MinorChecker ${ }^{\circledast}$ units were provided. A control community (Altoona) received neither MinorChecker ${ }^{\oplus}$ units nor the awareness campaign.

In association with the implementation of the MinorChecker ${ }^{\oplus}$ units in York, an awareness campaign concerning underage drinking targeted at youth was launched in York and Williamsport. The campaign consisted of media events, press releases, poster, flyers, and special events at conferences, colleges and malls. A special effort was made to target college students.

The impact of the card reader system on access to alcohol by minors and the incidence of alcohol-related problems was examined over a period of up to 24 months. Comparisons among the three communities were made on a variety of measures. These included a compliance check operation in which young-looking accomplices attempted to purchase alcohol, the number of charges for underage possession of alcohol, the number of DUI charges, and alcohol-involved traffic crashes. Focus groups were conducted with underage drinkers and with servers of beverage alcohol in each community before and after the implementation period. Interviews were also conducted with licensees who participated in the MinorChecker ${ }^{\circledast}$ program. In addition, data from the MinorChecker ${ }^{\oplus}$ units were examined to gain insights into how the system was being used. 


\section{Process Evaluation.}

The focus groups revealed that although young people had a general fear of the card reader system, they were determined to find a way to either avoid it or circumvent it. In general, they did not perceive the card reader system to be a significant barrier to their access to alcohol because they believed that retailers wouldn't spend the money to obtain the device, retailers and servers would not use it regularly because it would take too long to check cards, and/or the system would not read all cards. Many actually believed that most licensees were not interested in checking IDs very closely.

Licensees were split in terms of their opinions concerning the value of the card reader system: one group was very enthusiastic about the system; the other remained skeptical. The latter group perceived the system to be expensive, unreliable and redundant. The former group immediately saw the potential benefits of the system in terms of its ability to assist in their efforts to prevent sales to minors.

Over the course of the implementation period, 36,584 cards were scanned with the MinorChecker ${ }^{\circledR}$ units in York. The majority of licenses scanned were from Pennsylvania $(95.7 \%)$ but licenses from 21 other states plus the province of Ontario were represented in the records. Almost half of all cards were scanned between 8 PM and 11 PM. Licenses indicating an age of 21 were the most frequently recorded $(38.2 \%)$. Only $1.5 \%$ of records indicated someone under 21 years of age. Approximately $1.2 \%$ of records indicated an expired license, which is not considered to be a valid form of identification.

\section{Impact Evaluation.}

Young looking accomplices were hired to attempt to purchase alcohol in all three communities before the MinorChecker ${ }^{\circledR}$ units were installed in York and again 18 months later, during the implementation phase. The purpose of this compliance check was to determine whether or not the MinorChecker ${ }^{\circledR}$ program had an impact on the frequency with which young-looking patrons could purchase alcohol without being asked for identification.

Prior to the implementation of the MinorChecker ${ }^{\circledast}$ program, accomplices were able to purchase alcohol without being asked for ID on $16 \%$ of all attempts. Eighteen months later, they were able to purchase alcohol without being asked for ID on $48 \%$ of attempts.

It was expected that the awareness program combined with the MinorChecker ${ }^{\circledR}$ programs would lead to a systematic change in the approach to checking young patrons for ID that would be reflected in the frequency with which licensees asked young-looking patrons for ID. Clearly, this did not occur. In fact, following the implementation of the program, the rate of checking for ID actually decreased in York, as well as in the other two communities. 
Data on alcohol-related criminal and traffic offenses were obtained from the Administrative Office of Pennsylvania Courts Computerized Statewide District Justice System for comparable periods of time before and after the implementation of the MinorChecker ${ }^{\oplus}$ program. Although it might be expected that the program would serve to reduce access to alcohol among youth and thereby reduce their likelihood of arrest for underage possession and drinking-driving offenses, charges actually increased in all

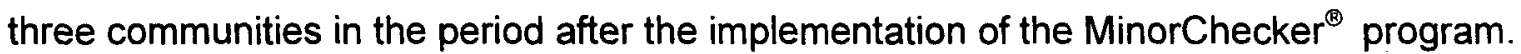
These increases in charges are most likely attributable to increases in enforcement activity.

Single vehicle nighttime (SVN) crash involvement was used as a surrogate for alcohol involved traffic crashes. The percent of SVN crashes among 16 to 20 year-old drivers in each community prior to the MinorChecker ${ }^{\oplus}$ program was compared with SVN crash involvement during a comparable period after the implementation of the program. SVN crashes among drivers age 21 to 30 were also examined over the same period of time. In York and Williamsport (the two program communities), SVN crashes among 16 to 20 year-olds decreased following the implementation of the MinorChecker ${ }^{\oplus}$ program. In Altoona (the control community), SVN crashes among this age group actually increased. By comparison, SVN crashes among 21 to 30 year-old drivers in York and Williamsport did not change substantially but decreased in Altoona. These changes, although consistent with the hypothesized effect of the MinorChecker ${ }^{\circledR}$ program, were not statistically significant.

\section{Discussion and Conclusions}

It was hypothesized that the implementation of the card reader system combined with an awareness program would serve to reduce the availability of alcohol to those under 21 years of age by increasing the frequency and efficiency with which licensees checked the IDs of patron. With the possible exception of the traffic crash data, there was little evidence to suggest that the program had a substantive impact on the incidence of alcohol-related problems among young people in the targeted community.

The absence of definitive evidence of a general positive impact of the implementation of the card reader system in one community should not detract from the apparent beneficial effects of the technology. The resounding endorsement of the device by many licensees attests to its value. The approach obviously has a role to play in the overall strategy to reduce the availability of alcohol to minors.

It should, however, be recognized that the card reader system is not a complete solution to the problem of underage drinking. Providing licensees with the means to check IDs quickly and easily serves to enhance the barrier between youth and alcohol. If used appropriately and consistently, this system has the potential to have an impact on the availability of alcohol to minors. 
Electronic card reader systems, such as the MinorChecker ${ }^{\circledast}$, are tools that have been developed to assist licensees in their efforts to prevent sales of alcohol to those under 21 years of age. Licensees who received a MinorChecker ${ }^{\circledast}$ unit as part of this study were divided in terms of their opinions of the device. One group was very enthusiastic about it and they used it regularly and often. The other group was highly skeptical about the value of the device. They perceived it to be unreliable and preferred to rely on their own abilities to identify underage customers and altered or counterfeit IDs.

The major limitation of the MinorChecker ${ }^{\oplus}$ program was not the technology but the user. The card readers performed as they were designed to perform. However, if the user lacks the desire or commitment to use the device consistently, it cannot fulfill its intended purpose. To be effective, it must be used as part of a comprehensive program to check the identification of every customer who appears under 30 years of age. This requires a strong policy and commitment by the management of the licensed establishment. Periodic enforcement or "compliance checks" conducted by an outside agency would reinforce and provide motivation for adherence to such a policy. 


\subsection{INTRODUCTION}

1.1. Background. Between 1982 and 1995, the number of 16 to 20 -year-old drivers involved in alcohol-related fatal crashes decreased by over $60 \%$-- from 4,337 in 1982 to 1,591 in 1995. Despite the significant reduction, young people continue to drive after drinking and crash as a result. For example, in 1998, 1,668 drivers aged 16-20 were involved in fatal crashes in which alcohol was involved; a further 21,000 were involved in alcohol-related injury crashes (NHTSA, 1999).

Prominent among the measures introduced to help reduce the number of deaths and injuries resulting from alcohol-related motor vehicle crashes during the 1980 s was the establishment of the 21-year minimum drinking age for alcohol in all states (Peters, 1997; Sweedler \& Moulden, 1986). In 1984, Federal legislation created strong incentives for all States to set the legal drinking age at 21, using highway construction funds as the lever. By November 1988, all States and the District of Columbia had raised the minimum legal drinking age (MLDA) to 21 years.

The diversity of these laws in the United States over time enabled researchers to study the effects of changing the MLDA from 18 to 21 . Numerous studies have documented the effectiveness of these laws in reducing the number of young drivers involved in alcohol-related crashes (e.g., DuMouchel, Williams and Zador, 1985; Hoxie \& Skinner, 1985; U.S. General Accounting Office, 1987). It has been estimated that between 1982 and 19874,500 lives (Fell, 1988; Sweedler, 1988) or "well over 1000 youth each year" (Toomey, Rosenfeld \& Wagenaar, 1996) were saved as a result of raised drinking ages.

But as successful as this measure appears to have been, it is also apparent that minimum purchasing ages have not prevented underage youth from drinking. The majority of adolescents still report using alcohol before it is legal for them to do so (Schulenberg et al., 1996). Numerous surveys indicate that a majority of high school students drink at least occasionally and that alcohol consumption increases sharply through adolescence (A Generation at Risk, 1997; O'Malley, Johnston \& Bachman, 1998). Analysis of the most recent data from ongoing national surveys in the U.S. found high rates of alcohol use and relatively low rates of complete abstention among U.S. adolescents (O'Malley, Johnston \& Backman, 1998). For example, the 1997 Monitoring the Future study found that $72 \%$ of $10^{\text {th }}$ graders (aged $15-16$ ) and $82 \%$ of $12^{\text {th }}$ graders (aged 17-18) reported having consumed alcohol in their lifetime. According to the 1997 Youth Risk Behaviour Survey, the rate of alcohol use increased steadily from $72 \%$ among $9^{\text {th }}$ graders to $84 \%$ among $12^{\text {th }}$ graders. Although minimum legal drinking age laws may have reduced underage alcohol use, it is apparent that underage drinking is still very common (Kusserow, 1991a; 1991b; Peters, 1997; Preusser, Ulmer \& Preusser, 1993; Smart, Adlaf \& Walsh, 1996). 
Furthermore, despite the adoption of the 21-year minimum legal purchase age in all States, young people continue to drink and drive. Johnson \& White (1989) indicate that $57 \%$ of 18 to 20 -year-old drinkers reported having driven drunk, $50 \%$ reported having consumed alcohol while driving, and almost $70 \%$ reported having driven a car after a couple of drinks.

These findings underscore the need for continued efforts to reduce the prevalence of drinking and driving among youth.

1.2 Access to Alcohol. Raising the legal minimum drinking age did not eliminate access to alcohol by young people but, rather, served to reduce the availability of alcohol and the public health problems associated with it. In fact, George, Crowe, Abwender and Skinner (1989) indicated that the law change probably had a minimal impact on the quantity of alcohol consumed by underaged drinkers but a dramatic effect on where they consumed alcohol. It is possible that because underage drinking is illegal, it is less likely to occur at bars, restaurants and other traditional drinking places, but more likely to occur at parks, beaches and in neighbourhoods, which are not primary patrol areas for traffic, highway and/or DWI officers. Perhaps that is why, despite lower youth DWI arrest rates (Preusser, Ulmer \& Preusser, 1992;1993), underage youth continue to drink and become involved in alcohol-related fatal and injury crashes (Kusserow, 1991b; Little \& Clontz, 1994).

It is not surprising that rates of alcohol consumption and alcohol-related problems and accidents among youth remain high because alcohol remains relatively easy for them to obtain. Research indicates that more than half of underage drinkers obtain alcohol from friends, who are often under 21 themselves (Preusser et al., 1995). Similarly, Wagenaar et al. (1996) found that the source of alcohol consumed on the last drinking occasion for $9^{\text {th }}$ and $12^{\text {th }}$ graders in Minnesota and Wisconsin was most often friends over 21 , followed by friends under 21 , home, and commercial outlets. A study of underage drinkers in Ontario, Canada reported that most found alcohol readily accessible (Smart, Adlaf and Walsh, 1996). Obtaining alcohol from parents' supplies (29\%) or having someone older purchase it (27\%) were both more common than self-purchase $(14 \%)$. Lewis, Lapham, and Skipper (1998) also reported that youth were much less likely (26\%) than adults to purchase alcohol, and that of those who did buy it, $63 \%$ purchased packaged alcohol as opposed to alcohol by the drink, probably from fear of detection, or because bars are perceived to be less likely than liquor stores to sell to underage persons (Wolfson et al., 1996). However, although direct purchase from commercial outlets is not the only or necessarily the most prevalent means of obtaining alcohol, it is an important alcohol access point. A significant number of underage persons (over $30 \%$ of high school students and over $60 \%$ of college students) reported having tried to buy alcohol (Preusser, Ferguson, Williams \& Farmer, 1995) and almost two-thirds of the students who drink reported buying their own beverages (Kusserow, 1991b). 
To a large extent, alcohol remains readily available to youth because of several factors: low levels of enforcement of the minimum drinking age; legal loopholes that permit underage drinking ${ }^{1}$; and the propensity of adults to supply alcohol to youth. In addition, although many states have statutes prohibiting non-parental adults from providing or selling alcohol to individuals under 21 , few adults face consequences for doing so. A study of criminal and administrative enforcement of the minimum drinking age in four states (Wagenaar \& Wolfson, 1994) found that actions against those who sell or provide alcohol to underage youth are infrequent. It was estimated that only 2 of every one thousand occasions of youthful drinking result in an arrest, and only 5 of every one hundred thousand youth drinking occasions result in an action against an alcohol outlet (Wagenaar \& Wolfson, 1993). Currently, the probability of a commercial outlet receiving any penalty for selling to minors is extremely low (Wagenaar \& Wolfson, 1995).

Penalties against youth who violate the laws ( $\$ 10$ to $\$ 5,000$ and/or 1 year in jail) are also often not a sufficient deterrent. Even when strict penalties exist, courts are often lenient and do not apply them (Kusserow, 1991).

The propensity of commercial alcohol outlets to sell alcohol to underage youth is welldocumented (Kusserow, 1991 ab; Preusser, Ulmer \& Preusser, 1993; Preusser \& Williams, 1992; Preusser, et al., 1994; 1995; Smart et al., 1996; Toomey et al., 1996; Wagenaar, et al., 1996; Wolfson et al., 1996). These studies demonstrated that a majority of alcohol outlets sell alcohol to individuals who appear younger than 21 without checking age identification. For example, in a study conducted during late 1990 and early 1991, 19 and 20-year-old males, who neither lied about their age nor used false identification, were able to purchase packaged beer at 97 of 100 retail outlets in Washington D.C., at 82 of 102 outlets in Westchester County, New York, and at 44 of 100 outlets in Albany and Schenectady counties, New York (Preusser \& Williams, 1992).

With many more potential underage purchasers than licensed retail outlets that sell alcohol, enforcement at the seller level should be more efficient than at the purchaser level. In addition, sellers can be subject to a greater range of sanctions and much more severe penalties, resulting in greater deterrent effects of the enforcement effort. Thus, enforcement targeted at the relatively few sellers may be a more efficient use of police resources and may have greater effect given the range of available sanctions that can be applied.

Enforcement actions taken against vendors who fail to require age identification has the potential to be an effective and efficient method for reducing underage access to alcohol. One very direct method for conducting seller-targeted enforcement is the "sting" or "decoy" operation, in which an underage person, working under the supervision of a

\footnotetext{
${ }^{1}$ Although it is illegal to sell alcoholic beverages to minors, in several states it is not illegal for minors to purchase, attempt to purchase, possess, consume, or sell alcohol and enter drinking establishments.
} 
police officer, attempts to purchase alcohol without lying about his or her age and without using false identification. Such operations have been conducted by several police agencies. Typically, about 50 to $75 \%$ of retail outlets targeted by the sting are cited for selling to an underage person. Subsequent and successive sting operations in the same communities show violation rates ranging from zero to about $35 \%$ (Preusser, Williams \& Weinstein, 1994).

Such seller enforcement programs, particularly those employing sting operations, have been shown to have a significant impact on underage sales (Preusser \& Williams, 1992; Preusser, Williams \& Weinstein, 1994; Preusser, Ferguson, Williams \& Farmer, 1995). However, sting operations, the purpose of which is to identify and penalize vendors that sell to underage youth, typically address the problem of retailers who do not require age identification prior to sale. Generally, they have not been designed to address the situation where the identification proffered is false, altered, or borrowed. Previous research has indicated that the use of false, borrowed, altered or counterfeit identification is not an uncommon method of obtaining alcohol (Preusser et al., 1995; Wagenaar et al., 1996) and a primary reason for easy access to alcohol from commercial sources.

According to Preusser et al. (1995), the available information indicates that the number of young people who have used false identification for the purchase of alcohol is substantial and varies widely across communities and states, probably due to differences in state law, penalties, and enforcement practices regulating the sale of alcohol to underage persons and the use of false identification. For example, a survey conducted in Minnesota and Wisconsin found that only $2.9 \%$ of high school seniors and 7.5\% of persons aged 18-20 "used a false ID last month" (Wagenaar et al., 1996). A survey conducted in New York and Pennsylvania found that, on average, about $21 \%$ of high school students and $48 \%$ of college students surveyed reported using some form of false identification (Preusser et al., 1995). Regarding the type of false identification used and how it was obtained, $14 \%$ of underage students reported using another person's real driver's license, $17 \%$ used a fake driver's license and $9 \%$ used some other form of false identification. Among those who used fake drivers' licenses, $10 \%$ obtained licenses from an official source by misrepresenting their age and/or identity; $9 \%$ altered an official license and $12 \%$ used a counterfeit license. These data indicate that false identification is easy to obtain and its use common.

1.3 Responsibility of Licensed Retailers. It is important to recognize that to a large extent, the onus of compliance with minimum purchase age laws rests primarily with licensed providers of alcohol. Licensed retailers are charged with the responsibility of ensuring that alcohol is sold only to persons who are of legal age. This requires that license holders request all potential customers who appear to be underage to furnish proof of their age. The motivation to comply with these requirements lies in the consequences of selling alcohol to someone who is not of age -- i.e., a fine and possible 
loss of one's license to sell or serve alcohol. However, as noted by Wagenaar and Wolfson (1994), the probability of a licensee being caught, convicted and sanctioned is exceptionally low.

Even among those licensees who are concerned and motivated to uphold their duty, restricting the sale of alcohol to persons who are of legal age presents a significant challenge. Licensees must make a reasonable effort to determine that every person is of legal age before selling or serving them alcohol. Licensees and their employees are, therefore, placed in the position of having to determine (1) whether or not the identification validates the person's claim to being of legitimate age and (2) the authenticity of the document(s) presented. This involves more than simply requesting an individual to provide proof of their age. An effort must also be made to determine the validity of a piece of identification. This can be a difficult and time-consuming task -- one for which many are unprepared.

Determining a person's age from an identification card (e.g., a driver's license) often involves doing mental arithmetic with dates. This can be challenging for even the most numerically skilled. For many, the process is not straightforward and can take some time. In a busy store or bar with several other customers waiting, the person checking the identification may feel considerable discomfort and pressure to hurry. The situation can easily result in mistakes. Some may simply not bother to do the arithmetic, either because it would take too long or because they feel no one would be so bold as to present identification that actually shows they are under legal age. Young people are well aware of the fact that the best time to attempt to purchase alcohol is when the store is crowded. This is when employees are often too busy to check identification and, when they do, it can be a superficial check at best.

Determining the authenticity of the identification can be even more difficult. As noted previously, among the most common means for young persons to obtain alcohol involves using altered, forged, and borrowed identification to deceive retailers about their age. To help alleviate the problem of bogus identification, many jurisdictions mandate that only certain pieces of identification can be used as proof of age when purchasing alcoholic beverages -- e.g., driver's license, military ID. But even these documents can be forged or altered. A quick search of the internet reveals literally thousands of opportunities to obtain realistic identification from any state or province. In many cases, these IDs are not easily recognized as counterfeit. Borrowed and/or expired identification can also be a problem. Even though the piece of required identification typically contains a picture of the individual, it is often possible for a person to resemble an older sibling to a sufficient extent that the identification can pass as legitimate. In addition, although it is likely that most providers of alcohol will readily recognize a driver's license from their own jurisdiction, it is not uncommon for a young person to present an out-of-state license or other piece of identification that is unfamiliar to the 
retailer or tavern operator. Forgeries of, or alterations to, these documents are even less likely to be detected.

In summary, enforcing compliance with minimum drinking age laws can be a difficult task, the onus of which is placed on retailers, distributors, tavern owners and their employees. The providers of alcohol are key players who are expected to make a reasonable effort to ensure that alcohol is only sold to those who are of legal age. This requires that licensees and their employees know the law and have the knowledge and capability to enforce it conscientiously and effectively. This requires that they be provided with the tools that will allow them to perform this task as easily, efficiently and effectively as possible.

1.4 An innovative approach: Using smart card technology. A recent technological innovation addresses the needs of licensed providers of alcohol to verify that their customers are of legal age and to identify altered and forged identification. The application of "smart card" technology to driver's licenses has resulted in a new style of driver's license that includes both a photograph of the individual to whom the license was issued and a magnetic stripe that contains information about the individual, such as name, date of birth, sex, height, license number and license expiry date. A device that reads the information on the magnetic stripe on the driver's license would provide alcohol beverage retailers with a simple, efficient and reliable system for verifying not only the age of the customers but also the authenticity of the identification presented.

In 1994, the Pennsylvania Department of Transportation began issuing a new style of driver's license that included both a photograph and a magnetic stripe on the back. The magnetic stripe contains information about the individual (e.g., name, date of birth, driver's license number, sex, height) that can be used to facilitate information transfer and enhance the security of the license. The Pennsylvania Liquor Control Board (PLCB) obtained the approval of the Pennsylvania Department of Transportation to use the information contained on the magnetic stripe driver's license in a system that would provide alcohol retailers with a means to determine the age of an individual as well the authenticity of the license to prevent sales to underage persons.

PLCB enlisted CommStar to develop the hardware and software for the "Minor Checker" ${ }^{\circledR}$ card reader system - the result is a simple, easy to use system that consists of a card reader and a microprocessor with a small printer. When a license is swiped through the reader, the software reads the information on the magnetic stripe to determine if the license is valid or expired. It provides immediate validation of the person's claim to be of age to purchase alcohol. The relevant pieces of information from the magnetic stripe can also be printed on a slip of paper for verification with that on the 
face of the license. A completed declaration of age $^{2}$ form can also be printed. A record of every transaction is saved on disk.

Widespread use of this card reader system for checking the identification/proof of age of persons attempting to purchase alcohol has the potential to have a significant impact on the sale of alcohol to minors. The primary objectives of this study were to implement and evaluate this innovative card reader system as a means to prevent sales of alcohol to those under 21 years of age.

This report describes the implementation and evaluation of a program to prevent sales of alcohol to minors using the MinorChecker ${ }^{\boxplus}$ card reader system.

\footnotetext{
${ }^{2}$ In Pennsylvania, licensees are encouraged to have the customer complete a Declaration of Age Card (PLCB-931) which states that the individual is of legal age to purchase alcohol and clearly specifies the penalties for misrepresentation. This card serves as a legal defense and protection in case the licensee, in "good faith", serves a minor who used a fake ID.
} 


\subsection{METHOD}

2.1 Overview. The evaluation of the card reader system involved a comparison among three communities in Pennsylvania. The card reader system was implemented along with an awareness and education program for both providers of alcoholic beverages and young people in the city of York, Pennsylvania. Williamsport received the awareness and education program but no card readers. The third community, Altoona, served as a control and received neither the card readers nor the awareness and educational programs.

2.2 Background. The sale of beverage alcohol in the state of Pennsylvania is regulated by the Pennsylvania Liquor Control Board (PLCB). In addition to operating 665 Wine and Spirits Shoppes, which are the exclusive retail distributors of wines and liquors in Pennsylvania, the PLCB licenses over 17,000 businesses throughout the state for either on-premise consumption of alcohol or off-premise sales of malt beverages. A quota system limits the number of licensed on- and off-premises retailers. One retail license is allowed for every 3,000 inhabitants in a municipality and one wholesale license is allowed for every 30,000 inhabitants of a county.

For the consumer, this means that liquor and wine can only be purchased for off-premise consumption from state-operated stores. Beer can be purchased in small quantities (i.e., six packs) at licensed restaurants and eating places or in larger quantities through privately operated distributors.

In Pennsylvania it is an offense for anyone under 21 years of age to purchase, attempt to purchase, possess, consume, or transport alcohol. It is also illegal to carry a false identification card and to lie about one's age to obtain alcohol. The penalty for a conviction is a fine of up to $\$ 500$ and offenders may be required to complete a program of alcohol education, intervention or counselling. In addition, offenders will have their driving privileges suspended for 90 days; a second conviction results in a one-year suspension; subsequent convictions lead to a two-year suspension.

Anyone under the age of 21 driving with a BAC of $.02 \%$ or higher can be charged with DUI. Those charged as adults (i.e., 18 to 21 years old) face a license suspension of one year, 48 hours in jail and a fine up to $\$ 5,000$. Offenders will also be required to complete an alcohol highway safety course. Those under 18 are sentenced by the juvenile court.

An adult who buys alcohol for anyone under 21 years of age or who makes or sells false identification cards can be fined $\$ 1,000$ for a first offense and $\$ 2,500$ for each subsequent offense. Licensees face similar penalties for selling alcohol to minors. 
However, licensees also face the potential suspension of their license to sell or seive alcohol.

Licensees are encouraged to request identification from anyone who appears to be under 30 years of age. If they are satisfied that the person is of legal age, they should also have the customer complete a PLCB-931 Declaration of Age card (see Appendix A). A properly completed PLCB-931 provides the licensee with a legal defense in the event that they are cited for serving alcohol to a minor.

2.3 Implementation. MinorCheckers ${ }^{\circledR}$ were provided to 60 of the approximately 130 eligible alcohol outlets in the city of York, Pennsylvania ${ }^{3}$. From the list of licensees, 75 potential participants were selected on the basis of their known or perceived likelihood of attracting a younger clientele. Local officials in the community were consulted to assist in the selection of licensees. In this context, some establishments were readily identified as targets; upscale restaurants and certain hotels were among the group of licensees not targeted for installation of the MinorChecker ${ }^{\circledast}$ units. All six stateoperated liquor and wine stores in York were included among the alcohol outlets selected to receive a MinorChecker ${ }^{\circledR}$.

Licensees targeted for inclusion in the project were sent a letter from PLCB inviting them to participate in this project. The invitation stated that if they agreed to participate, they would be provided with a MinorChecker ${ }^{\circledR}$ unit free of charge for a period of at least 18 months. Interested licensees were asked to call a toll-free number of arrange for installation of the device. Licensees who did not respond to the invitation within two weeks were contacted by telephone. If, after several attempts, a licensee was unwilling to participate, another licensee from the list was selected. The majority of licensees selected for the project agreed to accept the MinorChecker ${ }^{\circledR}$.

The first MinorChecker ${ }^{\circledast}$ unit was placed in a licensed establishment in March 1998 and all but five of the initial 50 the units were in operation by July 1998. The remaining units plus 10 additional units were placed over the next several months as licensees agreed to accept them.

Licensees who accepted the MinorChecker ${ }^{\otimes}$ also agreed to attend special sessions of the Responsible Alcohol Management Program (RAMP). RAMP is an ongoing educational program presented by the Pennsylvania Liquor Control Board for licensees and servers of alcohol. The objective of the program is to impart knowledge regarding preventive techniques and strategies to reduce drinking and driving as well as underage drinking, thereby reducing the number of alcohol-related highway injuries and fatalities. For licensees in York, these workshops were enhanced with an additional component to

\footnotetext{
${ }^{3}$ Private clubs, catering clubs, golf courses and other seasonal licensees were excluded from consideration.
} 
familiarize them with the MinorChecker ${ }^{\oplus}$ program and instruct them in the use and maintenance of the card reader system. As part of this additional component, an effort was made to generate greater awareness and understanding of the need for a program to prevent sales of alcohol to minors. The role of the MinorChecker ${ }^{\oplus}$ was highlighted as a means to assist them in their efforts to prevent sales to underage persons.

Posters concerning underage drinking were distributed to licensees. In addition, every licensee who participated in the study received widow/door decals identifying their establishment as a user of the MinorChecker ${ }^{\oplus}$. The intent of these displays was to discourage potential underage customers from even attempting to purchase alcohol.

The use of the system was monitored for a maximum period of 24 months. The shortest period was 15 months. During this time, regular contact was made with all licensees who had installed the system to ensure that it was being used correctly, to address questions and problems, and to gather data stored on the system for every transaction collected by the system.

2.4 Youth Awareness Program. In association with the implementation of the MinorChecker ${ }^{\oplus}$ units in York, an awareness campaign concerning underage drinking targeted at youth was conducted in York and Williamsport. The campaign consisted of media events, press releases, posters, flyers, and special events at conferences, colleges and malls. A special effort was made to target college students. For example, information about underage drinking was placed in packets for incoming freshmen in the fall of 1999, posters were displayed around campus and articles were placed in student newspapers. In addition, in York, every opportunity was used to set up a display on campus:and demonstrate the use of the MinorChecker ${ }^{\circledast}$. These displays -- particularly the MinorChecker ${ }^{\circledast}$ device itself - attracted considerable attention among students,. Numerous students volunteered to have their drivers' licenses swiped. These demonstrations served to illustrate very clearly the capabilities of the device.

2.5 Discussion. In the initial planning of this project, the goal was to saturate a community with MinorChecker ${ }^{\circledast}$ units by making one available to every licensed alcohol outlet. For several reasons, this proved to be elusive and largely unnecessary. First, with approximately 130 licensed alcohol outlets in the city of York, the cost of purchasing the required number MinorChecker ${ }^{\circledast}$ units would have been prohibitive. Second, because not every establishment had the same exposure to minors attempting to purchase alcohol, it was apparent that it was not necessary to place a unit in every establishment. For example, many upscale restaurants, hotels and private clubs were generally not frequented by young people for the purpose of purchasing alcohol. The locations of choice for young people were "six-pack shops", bars and restaurants catering to a younger clientele, and beer distributors. Hence, with the assistance of local officials (PLCB, police, other residents) it was possible to target the licensees most likely 
to be frequented by minors. Thus we were able to achieve virtual saturation from the perspective of young people in the community.

Participation in the MinorChecker ${ }^{\circledR}$ program was voluntary. Although every effort was made to encourage participation, a small number of licensees on the target list did not agree to accept a MinorChecker ${ }^{(\otimes)}$ unit. Typically, these licensees indicated that they weren't interested or they didn't "need" it. At least one suggested that the MinorChecker ${ }^{\oplus}$ program was yet another intrusion into his business by the licensing authorities.

Licensee turnover was an unexpected difficulty. Despite the popular perception that retail sales of alcoholic beverages is a highly lucrative business, it became apparent that it can be a somewhat fragile venture. During the course of the study, a small number of participating licensed outlets either closed or were sold without warning or notice. It was only through our frequent visits to participating licensees that we became aware of these changes. Typically, the new owner was not informed of the MinorChecker ${ }^{\oplus}$ study and we were in the position of having to negotiate with the new owner to retain the MinorChecker ${ }^{\star}$ unit and to train them in its use.

Discussions with licensees revealed that they were aware of other licensees who were not participating in the MinorChecker ${ }^{\oplus}$ program. Some expressed animosity toward these licensees because it reflected poorly on the industry as a whole. Others were content to simply keep minors out of their own establishments and to let others deal with the problems associated with serving alcohol to minors. Although not a universal sentiment, a majority of licensees participating in the study thought the MinorChecker ${ }^{\oplus}$ should be mandatory for all licensees.

In summary, it is obvious that the greater the number of licensees participating in the program, the greater the barrier to minors attempting to purchase alcohol. However, by targeting licensed establishments known or believed to cater to a younger clientele, as well as state-operated alcohol outlets and beer distributors, we were able to achieve a virtual saturation of the community with MinorChecker ${ }^{\circledast}$ units. The MinorChecker ${ }^{\circledast}$ units, combined with a program to encourage licensees to adopt a strong policy of checking IDs and a program to discourage underage youth from drinking, created a situation whereby it was increasingly more difficult for young people to purchase alcohol in the community. The effect of this program is discussed in the following sections. 


\subsection{EVALUATION}

3.1 Overview. As with any new program, it is equally important to understand how the card reader system worked as well as whether or not it produced the desired results. Hence, the evaluation examined both process and outcome features of the program. This involved the collection of information prior to the implementation of the MinorChecker system, during the time it was in operation, and again after its use had become stabilized in the community. The following sections present the findings from the Process and Outcome Evaluations separately.

3.2 Process Evaluation. The primary purpose of the process evaluation was to determine the factors that enhance or inhibit the ability of the card reader system to reduce sales of alcohol to minors. In this context, it was deemed important to understand how the card reader system was being used by licensees and the reactions of both licensees and young people to the system.

Information for the process evaluation was obtained from four sources: focus groups; ongoing monitoring of participating licensees; data obtained from drivers' licenses recorded by the MinorChecker ${ }^{\oplus}$; and interviews with licensees.

3.2.1 Focus groups. In lieu of a random telephone survey of youth, focus groups were conducted on two separate occasions in each of the three communities. The first set of focus groups, conducted immediately prior to implementation of the MinorChecker ${ }^{\mathbb{1}}$ in March 1998, involved 9 groups of 10 individuals representing four population groups:

- 16-17 year old males;

- 18-20 year old males;

- 18-20 year old females; and,

- beverage servers and distributors.

Only one focus group was conducted with 16-17 year old males. It became readily apparent that even though drinking was commonplace among this age group, they rarely, if ever, attempted to purchase alcohol themselves. Hence, this age group would not have been particularly affected by the implementation of the MinorChecker ${ }^{\circledast}$. The other groups scheduled with this population were replaced with groups of beverage servers and retailers.

A second set of focus groups was conducted in January and February 2000, just prior to the end of the MinorChecker ${ }^{\circledast}$ implementation phase. In each community, three focus 
groups were conducted - one with 18-20 year-old males, one with $18-20$ year-old females, and one with beverage servers and distributors. No focus groups were conducted with the youngest group of males (i.e., 16-17 year olds).

Focus groups provide qualitative information that is not intended to be statistically representative of the population. Rather, the information should be considered as providing interesting and useful hypotheses to be viewed in light of other supporting research and experience. The extended, in-depth interviews that comprise focus groups provide an opportunity to probe the participants' perceptions and emotions about the topic under consideration so as to gain a better understanding of reasons for, or reactions to, a particular situation.

The focus groups were conducted on our behalf by Warren Ashburn of Kelly Michener, Inc. (Lancaster Pennsylvania). Mr. Ashburn is a skilled focus group moderator and has had considerable experience in conducting similar groups with young people on the topic of alcohol consumption.

Each group session was approximately one hour in duration. All young participants were screened so as to include only those who admitted consuming alcohol. The session began with a "warm-up" discussion that involved participants telling stories of their own drinking. Although the purpose of the exercise was to have participants become more comfortable, it also served to help characterize their own drinking behaviour and that of their peers. The discussion then proceeded with the following topics:

- drinking venues;

- perceptions of drinking (e.g., why people drink; negative aspects of drinking);

- moral and legal aspects of drinking;

- access to alcohol;

- counterfeit/fake IDs; and

- the MinorChecker ${ }^{\circledR}$.

- Alcohol consumption patterns. It was apparent that drinking occupied a prominent place in the lives of these young adults. Drinking was seen as a group activity. They drank often and occasionally consumed sufficient alcohol to become intoxicated. Most had begun drinking by the age of 16 , and most perceived drinking to be the norm among their peers. Although a few indicated daily drinking, most confined their drinking to weekends -- defined as Thursday through Sunday. The amount of alcohol consumed per occasion was dependent upon the quantity of alcohol available -they drank everything they had. (After all, taking leftover alcohol home to store for another day wasn't a viable option for most young people!). 
Males reported more frequent drinking and drinking in higher quantities than females. Young women would often only have one or two drinks; young men rarely stopped after one or two.

For the most part, beer was the beverage of choice for young men but women preferred mixed drinks if they were available. However, the general consensus was that it didn't matter what you drank. The goal was to get a "buzz" and so they drank whatever they could get their hands on.

- Drinking venues. Anecdotal evidence from the participants suggested that most of their drinking occurred in a private setting (e.g., house, dorm) or in a secluded location (e.g., park, woods).

Drinking in public places was seen by many as an unnecessary risk. Sitting in a bar or restaurant consuming alcohol increased one's exposure to the likelihood of being caught. Nevertheless, among those who reported drinking in public, restaurants were viewed as an easy place to get alcohol, particularly if accompanied by adults. Somewhat surprisingly, the larger, well-known franchise restaurants were often seen as easy marks.

Experience in bars was limited but some have learned that certain establishments were very relaxed about the rules. This was particularly true of certain neighbourhood bars and "college" bars. Young females would often go to bars with their older boyfriends and had little difficulty being served.

- Perceptions of drinking. For young people, drinking is an activity in and of itself. Unlike older persons who usually consume alcohol as an adjunct to a social activity, for many of the young people who participated in the focus group sessions, drinking was a primary social activity. They drank to enjoy the pleasurable sensations of alcohol -disinhibition, euphoria, relaxation. Some indicated alcohol gave them greater confidence in dealing with each other, particularly the opposite sex. Several male participants admitted that the purpose of drinking was to get drunk. Although many denied strong pressure from peers to drink, there was a general sense that "everyone" did it.

The negative aspects of drinking were well known to most participants. Throwing up and hangovers were among the common responses. A sense of rage, committing violence, and doing things that made you "look bad" to your peers were also noted.

- Moral and legal aspects of drinking. All young participants were aware of the drinking age in Pennsylvania and all knew it was illegal for them to buy and consume alcohol. Many were also aware of the "zero tolerance" law for young drivers. Fewer 
than half, however, knew that it was illegal for them to attempt to purchase alcohol. Most assumed that the worst consequence of attempting to buy alcohol would be the embarrassment of being refused service.

There was some disagreement about the appropriateness of the drinking age. As might be expected, many participants thought that the drinking age was a good idea but that it should be lower than 21 . Interestingly, even among those who thought 21 was an appropriate age limit, they rationalized their own drinking by saying they only drank in private and no one got hurt. There was strong agreement that regardless of the drinking age, kids were going to drink and they had the means to obtain alcohol.

A consistent finding across all participants was a strong aversion to the notion of DUI. Although some admitted engaging in the behaviour on occasion, all condemned it and were fearful of the extreme penalties for being caught.

Many of the young participants were aware of the 90-day license suspension in Pennsylvania for drinking under age. The overall perception was that the likelihood of being caught was remote. They thought the police had better things to do than worry about kids drinking. And, if they were caught, they believed that the police would simply confiscate the alcohol and give them a warning.

Few young participants were aware of undercover enforcement programs (e.g. "Cops in Shops") designed to reduce underage drinking. Although some found the notion of undercover police officers chilling, they expressed skepticism about the ability of the police to cover a sufficient number of licensed establishments to be effective.

Beverage servers and retailers were generally quite knowledgeable about enforcement programs. None were pleased about these operations and viewed them as a form of entrapment. The antagonism between servers and the police and PLCB was blatantly obvious in the discussions.

- Access to alcohol. Obtaining alcohol did not appear to present a significant problem for the young participants. The most common means of obtaining alcohol was to have an older friend or sibling make the purchase. If necessary, they would go so far as to ask a stranger to buy alcohol for them.

Some participants mentioned pilfering from parents' liquor supply at home as a source of alcohol. Somewhat surprisingly, several participants indicated that their parents provided alcohol. According to participants, these parents would rather have their underage offspring and their friends consume alcohol at home under their supervision than in a unsupervised location that might possibly involve driving. 
Purchasing their own alcohol was less common among participants than having someone older buy it for them. When making a purchase, the best approach was to go boldly and confidently into the store without hesitation or fear. If asked for ID, they would say they left it in the car. Most often, however, their experience was that they were rarely asked. "Six-pack" shops were viewed as the easiest place to buy beer.

Distributors were riskier because they were seen as being far too diligent about checking ID. State stores (i.e., Wine and Spirits Shoppes) were simply out of the question as a direct source of alcohol. State store employees were very strict about checking ID. Not one participant admitted ever attempting to purchase alcohol at a State store.

Bars and restaurants were less common as drinking venues for participants. Some considered it a challenge to try to get served at a bar but most felt it was an unnecessary risk when it was so easy to obtain alcohol elsewhere. In each city, participants were aware of bars that had a reputation for serving minors ${ }^{4}$. A minority of participants (mostly males) frequented bars and seemed to enjoy that drinking atmosphere. Some females would visit bars/restaurants with their older boyfriends or with a group of other females who could bluff their way in or flit with the bouncer to gain access.

Young participants indicated that going to buy alcohol when it was busy offered the greatest chance of success. They knew that was when the clerk/server was least likely to ask for ID or look at it closely. Offering fast service took priority over checking ID. At take-out stores, clerks didn't want their customers to get irritated and take their business elsewhere. At bars/restaurants, slow service meant poor tips. Also, participants believed that younger clerks/servers, particularly those of the opposite sex, were least likely to hassle them about ID. Still others merely "went through the motions" of asking for ID without really looking at it.

Servers and distributors were all aware of the problem of minors attempting to purchase alcohol. Not surprisingly, all claimed that their establishments were very strict about not serving minors. Many had attended the RAMP sessions and were aware of enforcement efforts to catch establishments serving underage clients. They knew the penalties for a violation were severe and swore they would never knowingly serve a minor.

In contrast to the beliefs and experiences of the young participants who gave numerous illustrations of how easy it was to obtain alcohol, servers were adamant that it would be extremely difficult for minors to obtain alcohol at their establishment. They claimed to be very good at spotting minors and routinely asked for ID.

- Counterfeit/fake IDs. Fake, borrowed and/or altered IDs were not uncommon as a means to obtain alcohol. Borrowing someone else's ID or using an

\footnotetext{
${ }^{4}$ The establishments named by participants in York served to confirm many of our selections for installation of MinorChecker ${ }^{\circledR}$ units.
} 
older sibling's expired driver's licence were two of the most frequent techniques reported. Most had learned that photos on driver's licences were often so bad that they could look like almost anyone. Participants believed that most licensees don't scrutinize the picture but only check the dates. If the lighting is poor or there is a line-up, just about any ID will be accepted. Some participants were of the opinion that licensees didn't care if the ID you presented was any good, just so long as you had something to show them.

Virtually everyone knew of someone who had attempted to alter their driver's licence so as to make it appear that they were older. Although in Pennsylvania the date of the person's $21^{\text {st }}$ birthday is marked in red on the top of the front of the license, this marking is apparently easily removed. Altering the birth date was more complicated but could be done successfully. Some indicated that you could pay someone to do it for you.

Most participants knew where to obtain a counterfeit or forged ID. Entrepreneurs with equipment similar to that at state licensing bureaus apparently made regular visits to college campuses to sell their wares. For a price, these operators would produce a professional-looking driver's license (usually from a state other than Pennsylvania) with picture and lamination. The internet was also a rich source of counterfeit IDs. In fact, a quick search revealed thousands of sites where one could obtain a counterfeit ID. Females in the groups were much more likely than males to own a fake ID. Several participants spontaneously produced an altered or counterfeit license to show the group.

Many servers were confident that they could spot a fake or altered ID almost immediately. Some had difficulty believing that a counterfeit license could be so good as to avoid detection.

- The MinorChecker ${ }^{\circledast}$. The moderator introduced the MinorChecker ${ }^{\circledast}$ by passing around copies of a sheet describing the operation and purpose of the device. During the first set of focus groups, prior to the implementation of the MinorChecker ${ }^{\circledR}$ in York, none of the young participants were aware of it. Several of the servers had heard about the card reader system through the media, industry newsletters, or trade shows.

Virtually every young participant initially perceived the card reader as a genuine threat to their ability to obtain alcohol. Being technologically savvy, they were fearful that the magnetic stripe on their license contained more information than it does and that the card reader might automatically pass the information on to authorities which would precipitate sanctions. If they saw the device in a establishment, they said they would not take a chance and would leave immediately. The deterrent value of the system was readily apparent.

Several young participants were convinced that someone would eventually find a means to circumvent or fool the system. Indeed, it took only a few minutes for them to think of several potential (but not necessarily feasible or successful) ways to defeat the reader. 
The licensees and servers were generally in favour of this type of card reader system. They were, however, skeptical about the ability of the card reader system to perform as claimed. Some had seen a demonstration of the device and reported it was inconsistent and unreliable. Moreover, the cost was seen as prohibitive. If it wasn't mandatory to have one, the young people would simply find those places that didn't have one.

On a positive note, servers thought the mere presence of the card reader would discourage minors from attempting to purchase alcohol at their establishment. Having one was also seen as a way to get the Liquor Control Board "off their backs". Some recognized that the device would pay for itself if it prevented even a single fine for serving a minor.

- Second set of focus groups. The purpose of the second set of focus groups was to provide an indication of the nature and extent of changes in the thoughts, opinions, and professed practices of the target populations over the period of time the MinorCheckers ${ }^{\circledR}$ were in place. The structure of the sessions and topics discussed were the same as in the first set of focus groups with the exception that more time was allocated to a discussion of issues surrounding the use of the card reader system for checking IDs.

For the most part, there were no striking differences in the discussion about alcohol issues between the first and second set of focus groups. However, in the second set of focus groups, there was greater recognition of the card reader system among both young participants and servers. Interestingly, young participants in Altoona (the control community) were considerably better informed about the MinorChecker ${ }^{\circledR}$ than young participants in either York or Williamsport. At least half of all young participants who were aware of the system could name an establishment that had one. There remained a fear that the device would obtain more information about the individual than actually was encoded on the card. There was continued recognition of its general deterrent value.

On the other hand, young participants expressed a greater level of confidence in their potential to overcome or circumvent the system. In fact, some suggested that the system might ease their ability to purchase alcohol with someone else's ID because servers would come to rely on the system and not bother to check the picture.

Despite their fear of the device, underage participants generally believed that it would not have a large impact on their access to alcohol for a number of reasons:

- retailers would not spend the money to obtain the device;

- retailers might use it initially but would ease off with time;

- it would not read out-of-state licenses; 
- bars and package stores would be reluctant to use it because it would scare away customers who were of legal age;

- it would not read old, worn-out or scratched cards;

- it would take too long; and

- most places weren't interested in checking too closely anyway.

Among the servers who participated in this second set of focus groups, there emerged two relatively distinct groups-a small number who focused on the benefits of the system and a larger group who focused on its limitations. The major benefits of the system were:

- the powerful deterrent effect on attempts to purchase alcohol by minors;

- the potential to reduce fines for serving minors; and

- the security offered by a machine that determines the validity of the ID presented.

The primary limitations noted were:

- the perception of the extreme cost of the device;

- the perception that it was unreliable;

- the recognition that someone will eventually find a way to circumvent it;

- the perception that it takes too long to check an ID using the device;

- the belief that "we don't need it" because their own ability to spot underage and fake IDs is virtually foolproof; and

- the notion that they were far too busy most of the time to check everyone.

A few servers indicated that they had a MinorChecker ${ }^{\oplus}$ unit in their establishments. Most said it was used only sporadically. They believed that simply looking at the ID card was faster and just as accurate as the machine. Besides, the machine didn't read all cards and you had to check the picture anyway. Essentially, the MinorChecker ${ }^{\circledR}$ was unnecessary and inconvenient.

\section{Summary of Focus Group Findings}

- Drinking is common among those under 21 years of age.

- Most underage drinking occurs in private.

- Public drinking (in bars) is common among older subgroups but is seen as risky. 
- Young people seem to know where, when and how to purchase alcohol.

- Most underage purchases involve borrowed ID or no ID.

- Altered or forged IDs are less commonplace but most young people are aware of where and how to obtain a fake ID.

- Awareness of the MinorChecker ${ }^{\circledast}$ system was considerably greater among youth in the second set of focus groups - i.e., following implementation of the system in York.

- Young participants expressed a general fear of the card reader system for checking ID but were confident it would not prove to be a serious barrier to their attempts to obtain alcohol.

- Servers were split in terms of their opinions about the value of the card reader system: some perceived the system to be expensive, unreliable and redundant; others immediately saw the potential benefits of the system to assist in their efforts to prevent sales to minors.

3.2.2 Licensee Interviews. During the period in which the MinorChecker ${ }^{\circledast}$ units were deployed in York, informal discussions were held periodically with licensees to gauge their acceptance of the technology, and to determine problems with its use, perceived benefits, pattern of use, as well as any other observations about the system. At the conclusion of the study, semi-structured interviews were held with a number of licensees who had participated in the project.

To a large extent, the interviews confirmed what had become apparent during the focus groups-i.e., there appeared to be two distinct groups with opposite views on the value of the card reader system.

The first group was enthusiastic about the system. They saw it as an extremely useful and powerful tool. They used it regularly and often. Some indicated that on busy nights, they found it easier to set it up at the door and check everyone as they entered. It was apparent, though, that most did not use it all the time. After an initial period of frequent use, many simply used it as a "backup" to check those IDs about which they weren't completely sure. Even with the device at hand, many preferred to rely on their own judgement and only use the card reader as a second opinion or to print a proof of age declaration when they were uncertain. Using the MinorChecker ${ }^{\circledast}$ was often viewed as an extra step in the process of checking IDs. Unless there was some question about the ID presented, many simply preferred to rely on their own judgement.

Several licensees suggested that the card reader system should be mandatory. This would not only provide a level playing field for all licensees but would serve as a general deterrent to all young people. These licensees were convinced of the benefits of the 
MinorChecker ${ }^{\circledast}$ system for their own establishment but could also appreciate the societal value of a universal implementation of the system.

At the conclusion of the study, several licensees had arranged to purchase or lease the MinorChecker ${ }^{(}$system and continued to use it regularly. One purchased a card reader system from another manufacturer. Obviously, these licensees were convinced of the value of the system.

The second group was highly skeptical about the value of the MinorChecker ${ }^{\circledR}$ system. A common comment was that the system was too expensive. Many licensees said they simply could not afford to pay for such an expensive device - especially one that did not generate revenue. (Left unspoken was the notion that the purpose of the device was to limit their revenue by preventing sales to minors!). Although a few understood that the price of the MinorChecker ${ }^{\circledR}$ was comparable to the fine for serving minors, they believed the risk to be relatively low and they were willing to take their chances using their own method for checking IDs as they saw fit.

There was also a common perception that the MinorChecker ${ }^{\circledR}$ did not work properly. Several licensees had experienced the situation where a card could not be read. This could have been the result of a damaged or corrupted magnetic stripe. More common was the incomplete scan, whereby not all fields on the magnetic stripe were read. This causes the "Yes/No" lights on the device to blink alternately. (Simply pressing the "Yes" button would initiate printing of the partial data.). A damaged or corrupted magnetic stripe could prevent a license from being read completely. Even dirt on the card could prevent a complete scan. Counterfeit licenses would aiso be unlikely to have any information coded on the magnetic stripe. Many of these difficulties are easily overcome, and the solutions were addressed in training as well as in the user's manual supplied with each unit. Nevertheless, a number of licensees maintained the perception that the device didn't work.

It was noted by many participating licensees that the device was unable to read licenses from all states. Not all states have a magnetic stripe on their drivers' licenses and some that have a stripe do not code the information in a manner that can be read by the MinorChecker ${ }^{\oplus}$. Although some licensees indicated that many college students come from out of state, the vast majority of their customers were from Pennsylvania. Nevertheless, a software upgrade was provided to all licensees that allowed the MinorChecker ${ }^{\circledast}$ to read licenses from 18 states plus the province of Ontario.

Perhaps most disturbing were comments from licensees to the effect that they didn't need the system and that they were far too busy to check all IDs thoroughly. The degree of confidence many licensees/servers had in their own ability to spot underage, altered and counterfeit IDs was most likely overstated and unfounded. It can be a challenging task for even the most experienced server. There are numerous 
opportunities to miss something when checking IDs. For example, none of the servers indicated that they ever checked for an expired license, yet young people indicated that using an old (i.e., expired) licence of a sibling or friend was a common approach for obtaining alcohol.

The fact that servers indicated that they were often too busy to check all IDs suggests that they aren't particularly concerned about serving minors and/or they believe the card reader will take more time rather than streamlining the process.

In visiting licensees participating in the project, it was apparent that a small number had little interest in using the card reader system. In some establishments the device was not in sight - even relegated to a back room. One licensee even suggested that he agreed to accept the device as a means to keep the PLCB "off his case".

\section{Summary of Findings from Licensee Interviews}

- Among licensees who participated in the study, there were two distinct groups - those who were skeptical about the value of the card reader system, and those who were enthusiastic about it.

- Even among the enthusiasts, the MinorChecker ${ }^{\circledR}$ was often used as a backup to their own judgement about a particular individual and the ID presented, and/or to print a declaration of age.

- Price, reliability and time required were perceived as the main limitations of the system.

- Many of the skeptics were confident that their own ability to identify underage persons and altered or counterfeit ID was as good as, or better than, the card reader system.

3.2.3 MinorChecker ${ }^{\circledast}$ records. The MinorChecker ${ }^{\circledast}$ devices used in the study recorded information from every card swiped -- name, address, birthdate, license expiry date, state -- as well as the date and time of the transaction and the result --e.g., of legal age, underage, license expired. Every month or two, a project assistant visited participating licensees to download the data from the MinorChecker ${ }^{\circledR}$ units. These data were used to provide objective information about the frequency of use of the devices to check IDs, the characteristics of the persons who were asked for ID (sex, age, state of residence), and the result of the transaction (e.g., valid, underage, expired).

Over the course of the implementation period, over 50,000 transactions were recorded. In reviewing the dataset, it was apparent that there were numerous duplicate records resulting from the same card being swiped several times in rapid succession. In most cases, this appeared to be the result of the server swiping the same card repeatedly in 
order to read all the data on the magnetic stripe. (In virtually all cases, sufficient data were read on the first swipe to determine the person's age and expiry date of the license.) Hence, it was necessary to purge these multiple records leaving only one valid record for the individual. In addition, when a device was first installed, licensees typically tested the device and taught their employees how to use it by swiping their own licenses several times. These records, along with those known to be from project staff, were generally easy to identify and were deleted. The MinorChecker ${ }^{\oplus}$ unit could also be used to check the ID of persons wishing to purchase cigarettes. Because the minimum age for the purchase of tobacco in Pennsylvania is 18 , these records also had to be purged. After removing these records, the dataset consisted of 36,584 records.

Each record represents an attempt to purchase alcohol where the server asked for ID and used the MinorChecker ${ }^{\circledR}$ unit to determine the person's age and the authenticity of the license presented. It should be noted that the MinorChecker ${ }^{(\mathbb{B}}$ records do not present an exhaustive list of every attempt to purchase alcohol by a young person. Not included are attempts to purchase where: no ID was asked for or presented, service was refused without asking for ID; something other than a driver's license was presented; the server did not use the MinorChecker ${ }^{\circledR}$ to check the ID; or the ID either had no information recorded on the magnetic stripe or the information could not be read.

For the most part, the MinorChecker ${ }^{\oplus}$ records provide information about the people who were asked for ID when they attempted to purchase alcohol. The highly objective nature of the data may, however, give rise to a greater degree of confidence in the findings than is necessarily warranted. This is a result of the implicit assumption that the license actually belonged to the person presenting it as identification. As evidenced during the focus groups, this may not necessarily be the case. If the license was borrowed (or perhaps stolen), the demographic information recorded by the MinorChecker ${ }^{\circledR}$ would not be in concordance with that of the person attempting to purchase alcohol. Hence, some caution is warranted in reviewing the MinorChecker ${ }^{\circledast}$ records.

The records also do not indicate whether or not alcohol was provided to the individual whose license was swiped. It would be expected that no alcohol would be served to persons where the MinorChecker ${ }^{(-)}$revealed an underage person or an expired license. However, the server may also have refused service to someone who presented a valid license but questioned whether the license actually belonged to the individual.

- Frequency of Use. As indicated previously, there were 36,584 valid records from the MinorChecker ${ }^{\circledR}$ units over the study period. Figure 1 shows the monthly distribution of the number of cards scanned. Initial use of the device increased to a peak of approximately 2,000 scans per month and then decreased to a low of 700 one year after installation. Efforts to encourage use of the device were redoubled, including another set of RAMP sessions for licensees. Use of the device increased but the number of scans again began to decrease several months later. 


\section{Figure 1: \\ Number of Cards Scanned by Month and Year}

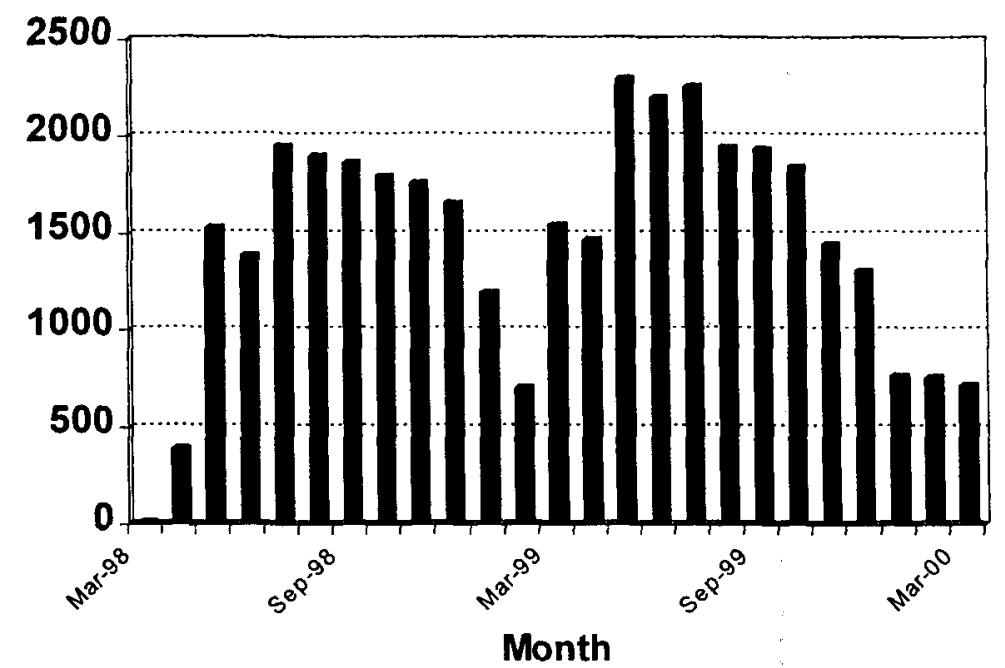

This monthly pattern of use suggests waning interest in the use of the device over time. Efforts to increase use were successful but only for a limited time. This pattern might reflect the comments of servers in the focus groups who indicated that as they became familiar with the MinorChecker ${ }^{\circledR}$ they did not use it all the time but rather used it as a back-up when they were not sure or when they simply wanted to print a copy of the declaration of age form. This pattern might also suggest a deterrent impact of the device. With regular use, underage customers avoid establishments where there is a high likelihood of being carded. Hence, there are fewer young people frequenting the establishments that had the device.

- State. The vast majority of all licenses scanned were from Pennsylvania (i.e., $95.7 \%$ ). Licenses from twenty-one other states plus the province of Ontario were recorded, the most frequent being Maryland, representing $3.3 \%$ of all records.

- Day of Week. Use of the MinorChecker ${ }^{\circledR}$ was lowest on Sunday $(5.1 \%$ of records) and increased throughout the week. Friday and Saturday had the greatest frequency of use with $26.9 \%$ and $29.7 \%$, respectively.

- Time of Day. Figure 2 shows the percent of MinorChecker ${ }^{\circledast}$ records according to time of day. As might be expected, the MinorChecker ${ }^{\circledR}$ was used most frequently during the evening hours -- i.e., between 8 PM and midnight (47.1\% of all records). The next most common time of use was between 4 PM and 7:59 PM (31.9\%), followed by the noon to $3: 59$ PM period $(9.9 \%)$. About $8 \%$ of all cards were scanned after midnight. 


\section{Figure 2: \\ Time Distribution of Cards Scanned}

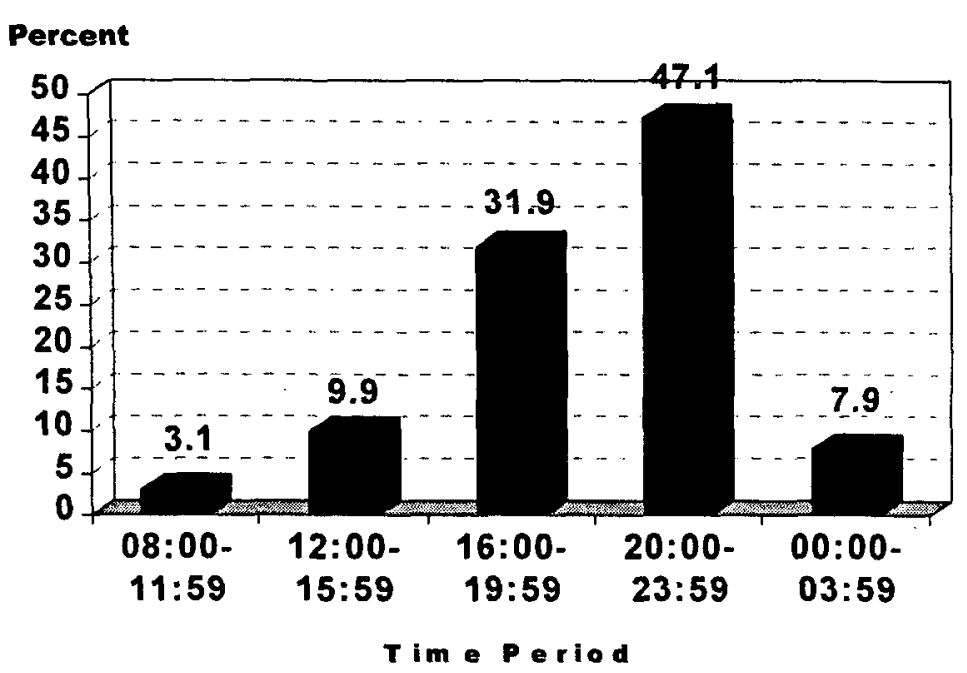

- Age. Figure 3 displays the age distribution from the MinorChecker ${ }^{\circledR}$ records. Licenses indicating an age of 21 were the most frequently recorded, representing $38.2 \%$ of all records. The frequency of recorded scans decreased as age increased.

Extremely few (1.5\%) records indicated someone under 21 years of age.

\section{Figure 3: Age Distribution From Cards Scanned}

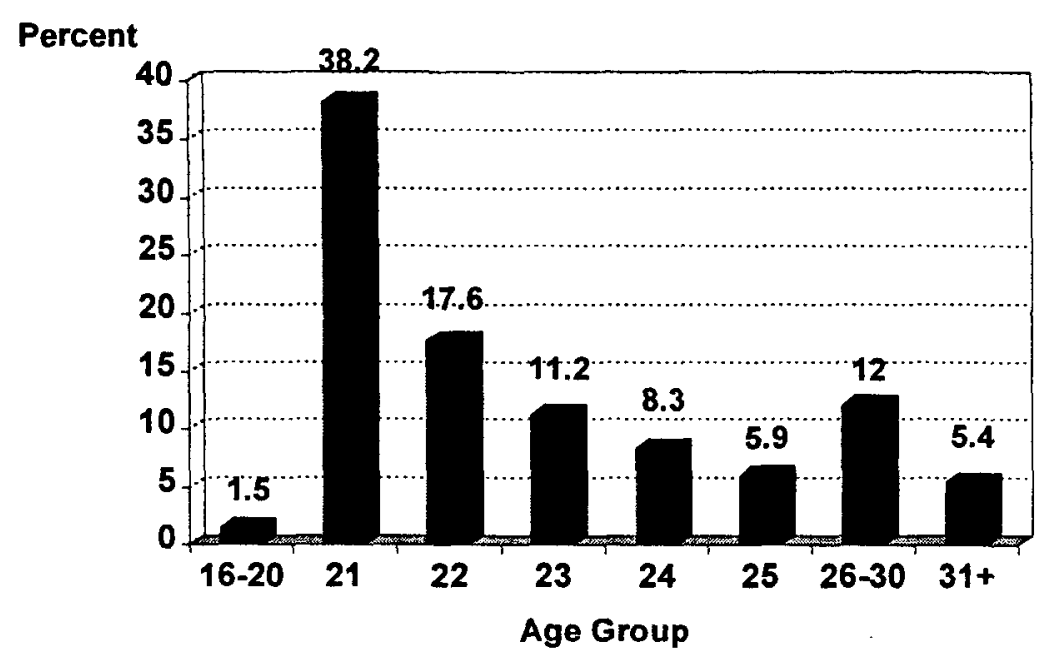

As indicated previously, the age distribution is derived from the date of birth recorded on the driver's licence and may not necessarily correspond with the age of the person presenting the license. Apparently, borrowing a license is a relatively common means used by young people to purchase alcohol. To the extent that this occurs, the age 
distribution presented in Figure 3 may misrepresent the age of persons attempting to purchase alcohol.

- Age and Sex. About two-thirds (67.5\%) of all cards scanned belonged to males. Figure 4 displays the age distribution separately for males and females. The overall pattern is similar for both males and females. However, the proportion of males is higher among those age 21 and 22 whereas the proportion of females is slightly higher among those 16 to 20 years of age and those 23 and over.

- Minors. In Figures 3 and 4, it is apparent that relatively few (i.e., 1.5\% or 562) of the cards scanned revealed a person to be under 21 years of age. Although some might expect that a system designed to detect underage drinkers would find a large number of minors, it is in fact surprising that the system revealed so many potential purchasers to be under 21. It is not particularly obvious why someone under 21 years of age would present their license as proof of age when it would reveal them to be under the legal minimum purchase age. One possibility is that some young people believed the server would not check the license closely and that simply presenting the license might be sufficient to convince the server that they were of legal age. Another possibility is that an attempt had been made to alter the information on the face of the license to make it appear as though the bearer was at least 21 . By reading the information from the magnetic stripe on the back of license, the MinorChecker revealed the true age of the individual.

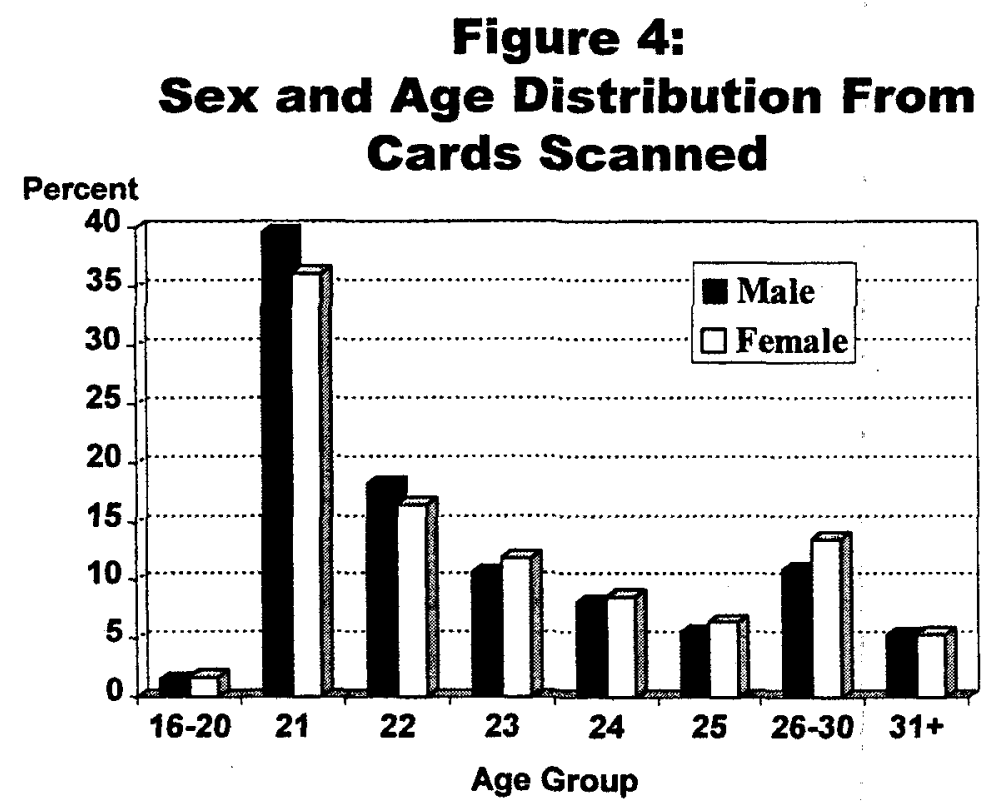

Examination of the date underage licenses were scanned revealed that almost half were identified during the first six months of the program. This suggests that young people may have become aware of the MinorChecker ${ }^{3}$ system and its ability to detect altered 
licenses and, therefore, discontinued using such cards in their attempts to purchase alcohol.

- Expired licenses. Approximately $1.2 \%$ of MinorChecker ${ }^{\circledR}$ records revealed an expired license. Undoubtedly, some of these were the result of a failure to renew one's license in a timely manner. Indeed, college students living away from home might not have received notice of the need for renewal or were unable to return to their home state to renew. Nevertheless, there remains the possibility that an underage person had obtained the old, expired license of an older sibling or friend and was using it to purchase alcohol.

During the interviews with licensees, it was noted that very few ever checked the expiry date prior to having the MinorChecker ${ }^{\circledR}$ installed. Some were not aware of the possibility that an expired license might be used by another person in an attempt to purchase alcohol.

3.2.4 Discussion. The greatest challenge in implementing the MinorChecker ${ }^{\circledast}$ program was getting licensees to use the device consistently. Although many accepted the device, some remained skeptical of its value and preferred to rely on their own skill and judgement in checking IDs. Even among those who were enthusiastic about the card reader system, several used the device primarily as a back-up to their own judgement or as a means to complete the Declaration of Age card (PLCB-931) quickly and easily. The technology works well; its limitation lies primarily among those who are expected to use it.

The MinorChecker ${ }^{\circledast}$ system appears to have deterrent value. In the focus groups, young people indicated they would avoid any alcohol outlet that they knew was using the card reader system. Several licensees indicated that they had experienced situations where young people have asked them not to scan their licenses with the MinorChecker ${ }^{\oplus}$ unit. Others were reported to have simply walked away when they saw the MinorChecker ${ }^{\circledR}$ unit.

3.3 Outcome Evaluation. The primary purpose of the outcome evaluation was to determine the extent to which the card reader system had an impact on access to alcohol by young people and the incidence of alcohol-related problems among youth. The evaluation design involved a comparison among three communities: York, which had the MinorChecker ${ }^{\oplus}$ units and an awareness program about underage drinking; Williamsport, which had the awareness program only; and Altoona, which served as the control community - i.e., no MinorChecker ${ }^{\oplus}$ units and no awareness program. Several measures were used to determine the impact of the program: a compliance check; charges for alcohol-related offenses among youth (including DUI); and alcohol-involved traffic crashes. 
3.3.1 Compliance check. To determine the extent to which the implementation of the MinorChecker ${ }^{B}$ units changed the degree of difficulty young people experienced in attempting to purchase alcohol, a compliance check was conducted in all three communities prior to the implementation of the card readers (i.e., March/April 1998) and again 18 months later (i.e., October/November 1999). This involved having young-looking individuals attempt to purchase alcohol at a variety of licensed establishments in each community. The purposes of the compliance check were:

- To determine the frequency with which licensees asked for identification from young-looking patrons;

- To determine the frequency with which licensees were willing to sell alcohol to young-looking patrons without checking their ID (whether it was asked for or not);

- To determine the extent to which the awareness program and the installation of the MinorChecker ${ }^{\oplus}$ units had an impact on the frequency of asking for ID; and,

- To assess the degree of scrutiny given licenses that were presented as proof of legal age.

- Method. Four college students (two males, two females) were hired as "patrons" to conduct the compliance checks. Each was at least 21 years of age and had a youthful appearance such that it was not obvious that they were of legal age to purchase alcohol. None of these young people resided in any of the target communities nor did they frequent any licensed establishment in these communities.

Prior to the start of each compliance check operation, a training session was held for the hired patrons. This session outlined the goals and objectives of the exercise and the procedures to be followed. Role-playing was used to have patrons become familiar with a number of different scenarios. The young patrons were then accompanied to a nearby establishment to practise the procedures, including the recording of data. Each attempt to purchase was then discussed with the entire group.

Patrons worked in mixed sex pairs. While in the field, each pair was accompanied by a local official from PLCB. This was to ensure the safety of the hired patrons as well as to assist them in locating all targeted establishments in each community.

Visits were made to licensed establishments between the hours of 3 PM and 10 PM on Friday and Saturday nights. At off-premise establishments, each member of the pair was to enter the premises and attempt to purchase an alcoholic beverage. Hired patrons did not enter the establishment together but separated their visits by 
approximately five minutes. At on-premise establishments, the pair would enter and sit together at the same table. Each was to order an alcoholic beverage.

The key variable recorded for each attempted purchase was whether or not they were asked for proof of age. If they were not asked, the purchase was completed. If asked, hired patrons were to alternate between presenting their driver's license and stating they left it in the car. If ID was presented, patrons were to take note of how closely it was examined and whether or not the license was scanned in the MinorChecker ${ }^{\circledR}$.

Licensed establishments in Williamsport and Altoona were selected using the same criteria as were used in York to identify establishments for installation of the MinorChecker ${ }^{\circledR}$ units - i.e., they were known or believed to cater to a younger crowd and/or were known to have had problems associated with serving alcohol to minors.

- Results. In the first study (in March/April 98), 245 attempts to purchase were made at 140 licensed establishments -- 49 in York, 52 in Williamsport and 39 in Altoona. In the second study (in October/November 99), 203 attempts to purchase were made at 131 licensed establishments -- 49 in York, 44 in Williamsport, and 39 in Altoona.

Several other establishments were on the list to be visited; but for a variety of reasons no attempt to purchase was made. For example, in some cases, the establishment was either closed or there was a line outside indicating that the establishment was at full capacity. In other cases, it would have been inappropriate for one or both to enter. Hired patrons were instructed not to enter any establishment they perceived might pose a threat to their personal safety.

Figure 5 displays the percent of attempts to purchase in which ID was not requested separately for each of the two compliance check operations according to community. Prior to the implementation of the MinorChecker ${ }^{\otimes}$ units, hired patrons were able to purchase alcohol without being asked for ID on $16 \%$ of all attempts. The likelihood of being asked for ID differed by community. In York and Williamsport, patrons were not asked for ID about $20 \%$ of the time; in Altoona patrons were able to purchase alcohol without presenting ID on only $5 \%$ of all attempts $\left(X^{2}=8.35, p<.02\right)$. It is not known why licensees in Altoona were more likely to check for proof of age than in the other two communities.

Following the implementation of the MinorChecker ${ }^{\circledR}$ units in York, hired patrons were able to purchase alcohol without being asked for ID on $48 \%$ of all attempts, considerably higher than during the previous compliance check $\left(\mathrm{X}^{2}=33.8, \mathrm{p}<.01\right)$. The differences in the rate of checking for ID did not differ among the three communities $\left(X^{2}=5.8, p>.05\right)$. 


\section{Figure 5: \\ Percent of Attempts to Purchase Where ID was not Requested}

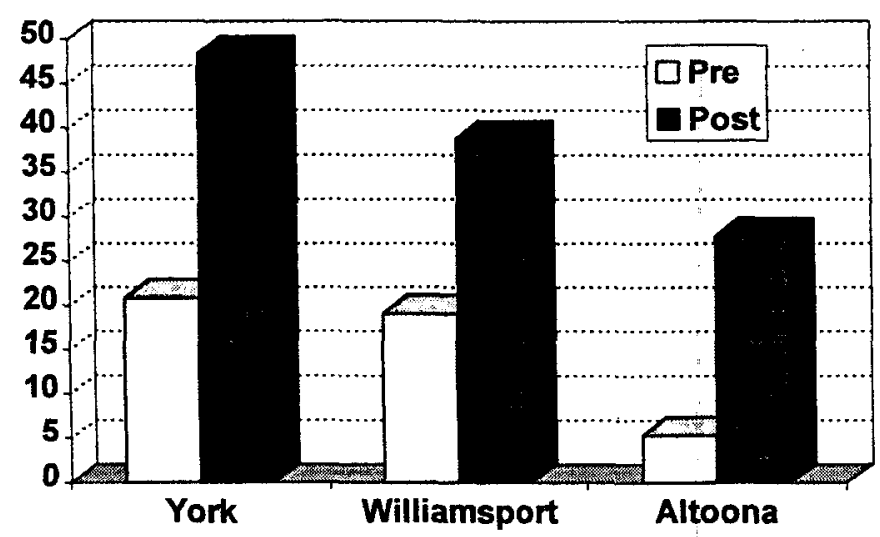

- Additional findings. Additional data collected during the compliance check operation provided interesting information about the factors that might influence a licensee's decision whether or not to ask for proof of age. For example, hired patrons were most likely to be asked for ID at a beer distributor $(81.8 \%)$ or PLCB store $(80 \%)$ and least likely to be asked at a "six-pack" shop (69.3\%) or when attempting to purchase a drink in a bar $(58.1 \%)$.

The likelihood of being asked for ID did not differ according to the estimated age of the server. Female servers were, however, less likely than male servers to ask for ID and were less likely to ask male patrons than female patrons.

Hired patrons observed a MinorChecker ${ }^{\circledR}$ in 46 establishments -- 41 in York; 4 in Williamsport; and 2 in Altoona. On $35 \%$ of these occasions, the MinorChecker ${ }^{\circledR}$ was used by the server to check the ID of the patron.

Interestingly, on $8.5 \%$ of attempts to purchase in which the server asked for ID, the hired patrons were able to complete the purchase without presenting ID. Hired patrons merely responded by saying they forgot their ID in the car and would have left without making a purchase if the server had not indicated that it was not necessary. It is, however, somewhat curious as to why a server would bother to ask for ID but not follow through.

For accounting purposes, hired patrons were asked to retain the receipt for all purchases. On 21 of $119(17.6 \%)$ of purchases where ID was not requested, patrons noted that the server did not provide a receipt. On every occasion that ID was shown, a receipt was provided. Speculation on the reasons for this oversight might lead one to suggest that servers are attempting to protect themselves by not providing evidence of where the alcohol was purchased in the event that the customer was caught with the product. 
- Discussion. It was expected that the compliance check would reveal a higher rate of patrons being asked for ID in York relative to the other communities following the implementation of the MinorChecker ${ }^{\boxplus}$. It was assumed that the awareness program combined with the MinorChecker ${ }^{\circledast}$ would lead to a systematic change in the approach to checking young patrons for ID that would be reflected in the frequency with which they asked young-looking customers for proof of age. Clearly, this did not occur. In fact, the rate of checking for ID actually decreased in York, as well as in the other two communities.

To some extent, the unexpected increase in the frequency with which the hired patrons were able to purchase alcohol without being asked for ID may be a function of the season in which the compliance checks were done. The first check was conducted in the fall; the second was conducted 18 months later in the spring. In the fall, licensees might have been more vigilant about checking young-looking patrons for ID as a result of the influx of new college students at the beginning of the new school year. By spring, licensees might have been more comfortable about having discouraged underage customers earlier in the year and became less likely to check for ID.

The increase in the frequency with which hired patrons were able to purchase alcohol in York without being asked for ID may have been a function of the degree of comfort afforded licensees with the MinorChecker ${ }^{\oplus}$. Simply having the device available might have led licensees into a false sense of security, believing it deterred underage customers from even attempting to purchase. This would not, however, explain the similar changes in the frequency of requesting ID in the other two communities.

Alternatively, there may be nothing systematic about the approach licensees use in checking for ID and the results reflect random fluctuation. The frequency of checking for ID may vary as a function of the attitudes and perceptions of particular employees, the number of customers in the store at the time, the financial state of the business -- factors over which we had no control in the present study.

The results may also be related to the characteristics of the hired patrons used in the two compliance check operations. Although there was no reason to believe that the appearance of the hired patrons differed substantially in the two operations, there may have been other less obvious differences such as poise, confidence and composure. Only one of the patrons was the same for both compliance check operations. Although this person was 23 years of age at the time of the second compliance check, she maintained a very youthful appearance and was, indeed, the patron most frequently asked for ID.

3.3.2 Alcohol-related offenses. Data on alcohol-related criminal and traffic offenses were obtained from the Administrative Office of Pennsylvania Courts Computerized Statewide District Justice System for the years 1995 through 1999. By far 
the majority of these offenses were for underage purchase, consumption, or possession of alcohol (94\%); only $4 \%$ were for drinking-driving offenses. The number of charges for other offenses, such as misrepresentation of age, selling or furnishing alcohol to minors, and carrying false ID was negligible. The data were obtained for the three counties that included the communities participating in the study - Blair (Altoona), Lycoming (Williamsport), and York (York).

From the data available, we selected a period corresponding to that during which the card readers were in operation in York (from April 1998 to December 1999) and a comparable period prior to the implementation of the card readers (from April 1996 through December 1997). Non-sequential time periods were selected to ensure that any potential seasonal variation in charging practices did not have an influence on the findings.

Table 1 displays the number of charges for underage purchase, possession or consumption of alcohol for the three counties during the 21-month periods before and during the implementation of the card readers in York. Population estimates of 15 to 20 year olds were obtained for each community for the years 1997 and 2000 . These were used to standardize the number of charges per 1,000 residents in the affected age group.

\section{Table 1}

Number and rate of charges for underage purchase, possession or consumption of alcohol in the three counties before and after the implementation of the card reader units

\begin{tabular}{|c|c|c|c|c|c|c|}
\hline & Charges' & $\begin{array}{l}\text { Pre } \\
\text { Pop } \\
15-20^{2}\end{array}$ & $\begin{array}{l}\text { Rate per } \\
1000\end{array}$ & Charges & $\begin{array}{l}\text { Post } \\
\text { Pop } \\
15-20\end{array}$ & $\begin{array}{l}\text { Rate per } \\
1000\end{array}$ \\
\hline & 834 & $5=10,134$ & 82.3 & 1,354 & 10,689 & 126.7 \\
\hline Willian & 650 & 5,336 & 121.8 & 732 & 5,319 & 137.6 \\
\hline Altoona & 595 & $\begin{array}{r}6,846 \\
\end{array}$ & 86.9 & $=673$ & 6,981 & 96.4 \\
\hline
\end{tabular}

${ }^{1}$ Charges are for the entire county.

2 Population figures are for 15 to 20 year olds for the city only.

Prior to the implementation of the card readers, the number of charges was comparable in Lycoming County (i.e., Williamsport) and Blair County (i.e., Altoona) but was considerably higher in York County. To a large extent, the higher number of charges in York was related to the larger population in York. When the number of charges were standardized by the number of 15 to 20 year olds in the population of the target 
communities in each county ${ }^{5}$ the number of charges per 1,000 population was comparable in York and Altoona but was considerably higher in Williamsport.

Following the implementation of the card readers, the number and rate of charges increased dramatically (i.e., over $50 \%$ ) in York county. Smaller increases (i.e., about $13 \%$ ) were evident in the other two counties.

Figure 6 shows the number of offenses in each county by quarter from 1995 through 1999. It is evident in the figure that the number of charges for underage purchase, possession or consumption is highly variable. Following the implementation of the MinorChecker ${ }^{\circledast}$ units in York (shown as a vertical line at the end of the first quarter of 1998), there was a substantial increase in charges in that community, but not in the other two communities.

\section{Figure 6:}

\section{Number of Charges for Underage Possession of Alcohol by Quarter}

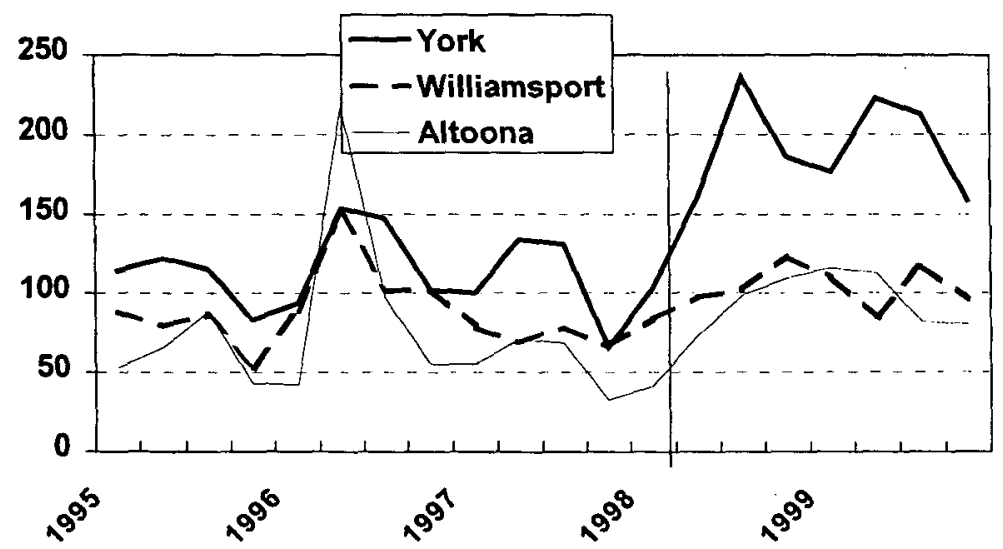

Table 2 displays the number and rate of charges for drinking-driving charges in each of the three counties during the 21-month periods before and during the implementation of the card readers. Prior to the implementation of the card readers, the number and rate of charges were comparable in all three counties. Following the implementation of the card readers, the number and rate of charges increased dramatically (i.e., over $150 \%$ ) in York and Altoona. A smaller increase (i.e., about 44\%) was evident in Williamsport.

\footnotetext{
${ }^{5}$ The population of $15-20$ year olds was not available on a county-wide basis. Population figures for the communities provide estimates that are most likely proportional to the population in the county.
} 


\section{Table 2}

\section{Number and rate of charges for drinking-driving offenses among persons under $\mathbf{2 1}$ years of age in the three counties before and after the implementation of the card reader units}

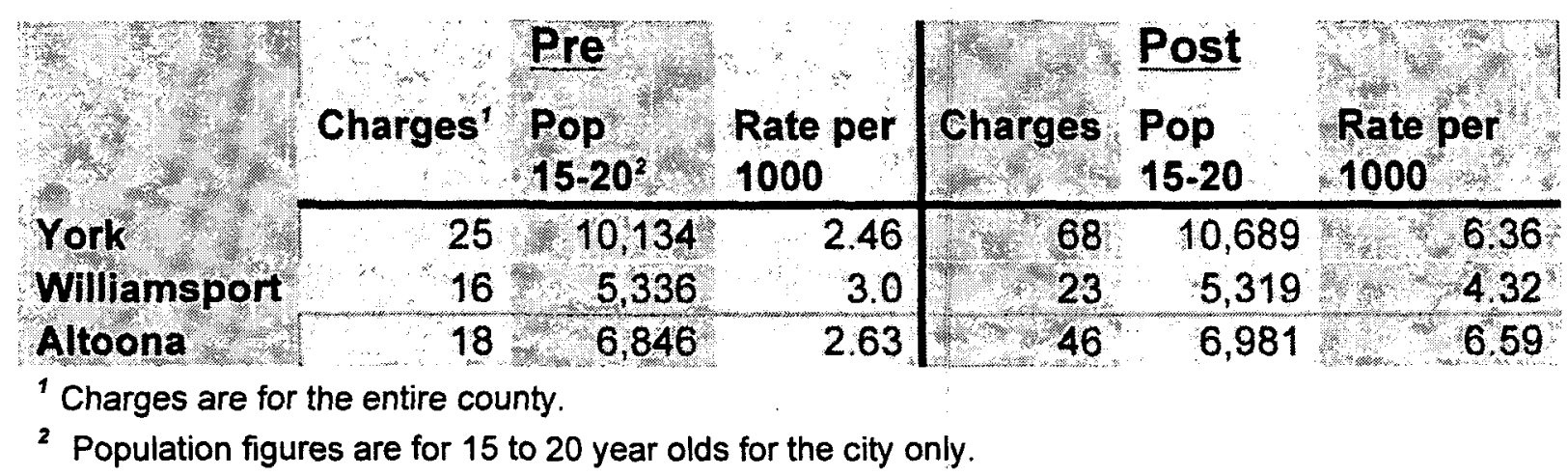

- Discussion. It might be hypothesized that the widespread implementation of the MinorChecker ${ }^{\text {to }}$ units in York would serve to reduce access to alcohol among youth, thereby reducing their likelihood of arrest for underage possession and consumption as well as driving after drinking. This, in turn, would lead to a reduction in the number of charges for these offenses. If this were the case, we would expect to see a reduction in charges in York, less of a reduction in Williamsport, and no change in Altoona. This was clearly not the case.

Alternatively, it might be hypothesized that the device would serve to increase the ability to catch offenders so that charges would increase initially. As awareness of the devices spread, charges would decline. Figure 6 provides some evidence to support this hypothesis. The number of charges for underage possession increased immediately following the implementation of the card reader units in York and declined somewhat thereafter.

In examining data on offenses, it is important to recognize that the relationships between access to alcohol, drinking behavior and arrests for these offenses are neither simple nor direct. Offense data do not necessarily reflect the incidence of the behaviour. With these types of offenses, it is generally presumed that there are many more transgressions of the law that never come to the attention of the police and/or never result in an arrest. Hence, offense data generally reveal more about police enforcement activity that they do about criminal behavior.

The increases in the reported incidence of the two offenses shown in Tables 1 and 2 are most likely attributable to increases in enforcement activity, particularly in York. It is not known the extent to which the increased vigilance among enforcement agencies may have been attributable to the extensive publicity surrounding the implementation of the MinorChecker ${ }^{\oplus}$ units throughout the city. 
3.3.3 Alcohol-related traffic crashes. Data on driver involvement in traffic crashes in the three target communities from 1995 through 1999 were obtained from the Pennsylvania Department of Transportation. These data included all crashes involving drivers between 16 and 30 years of age.

From the data available, we selected a period corresponding to that during which the card readers were in operation in York (i.e., April, 1998 to December, 1999) and a comparable period prior to the implementation of the card readers (i.e., April, 1996 through December, 1997). Non-sequential time periods were selected to ensure that any potential seasonal variation in traffic crashes did not have an influence on the findings.

Alcohol involvement by drivers was reported by the investigating police officer in only $5.6 \%$ of all crashes. Although police-reported alcohol involvement is generally regarded as a sensitive measure (i.e., it reflects true alcohol-positive cases), it laks specificity (i.e., many alcohol-positive cases are missed). These missed cases result in an underestimate of the number of alcohol-involved crashes.

To compensate for this under-reporting, a surrogate measure of alcohol involvement is often employed. A commonly used surrogate is the number of single vehicle nighttime (SVN) crashes (Douglas and Filkins, 1974). A high proportion of such crashes have been shown to involve a drinking driver. The number of SVN crashes often provides a better estimate of the number of alcohol-involved crashes than identified through police reports.

Figure 7 displays the percent of SVN crashes involving drivers aged 16-20 in each community in the period before and after the implementation of the card reader units. (The percent of SVN crashes was used to compare communities of different size.) In

Figure 7:
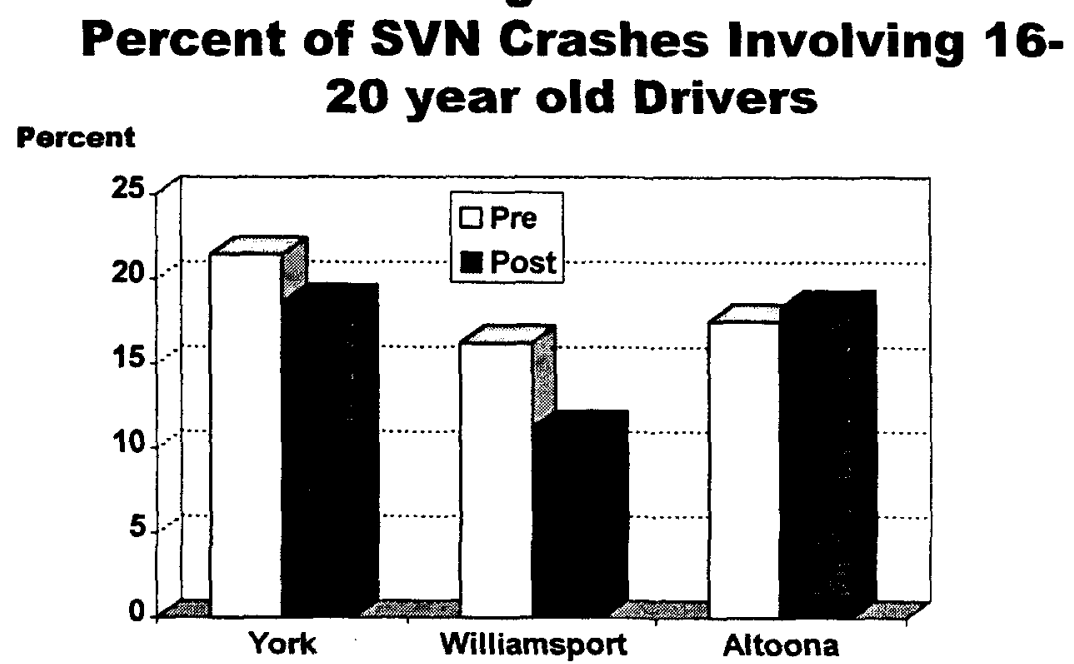
York, the primary intervention community, there was a $13.1 \%$ reduction in the proportion of SVN crashes among 16-20 year old drivers. Williamsport experienced a $30 \%$ reduction and Altoona (the control community) showed a $4.6 \%$ increase.

Figure 8 shows the percent of SVN crashes involving 21 to 30 year old drivers in each of the three communities before and after the implementation of the card readers in York. The availability of alcohol to drivers in this age group would not have been affected by the presence of the card readers in York or the awareness campaigns in York and Williamsport.

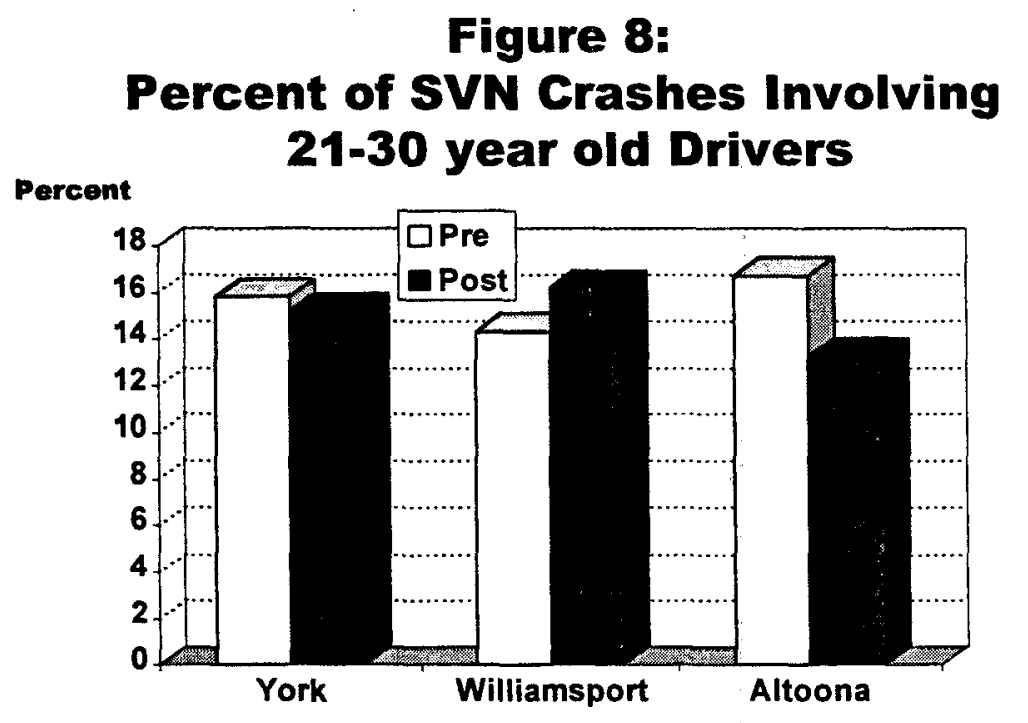

Among drivers age 21 to 30 in York, there was a $4 \%$ decrease in the proportion of SVN crashes. (This contrasts with the $13 \%$ decrease among 16 to 20 year old drivers shown in Figure 7.) In Williamsport, there was a 13.3\% increase in SVN crashes among 21-30 year old drivers. (This contrasts with a $30 \%$ decrease among 16 to 20 year old drivers). In Altoona, 21 to 30 year old drivers experienced a $20.3 \%$ decrease in SVN crashes, compared with a $4.6 \%$ increase among $16-20$ year old drivers.

Table 3 presents the results of the analysis of the traffic crash data separately for each community. The first column of the table shows the time period (i.e., before and after implementation of the card readers) and the age group (i.e., $16-20$ or 21-30) represented in each row. The next two columns list the number (and proportion) of non-SVN and SVN crashes, respectively. The ratio of SVN to non-SVN crashes is presented in the fourth column. The fifth column shows the odds ratio of the after period relative to the before period, followed by the standard error of the odds ratio in the sixth column. The final two columns list the $95 \%$ confidence intervals for the odds ratio. An interval that includes the value 1.0 is not considered statistically significant. 
As a means to compare the change in the proportion of SVN crashes among 16-20 year olds to the change in SVN crashes among drivers 21 to 30 years of age, the final row in the table for each community presents the ratio of odds ratios along with the $95 \%$ confidence interval. This ratio represents the change in SVN crashes among 16-20 year old drivers following the introduction of the card readers, relative to that among drivers 21 to 30 years of age. An odds ratio less than 1.0 indicates a relative reduction in SVN crashes among 16-20 year olds; a value greater than 1.0 indicates a relative increase.

The analysis reveals that SVN crashes among 16-20 year old drivers in York and Williamsport decreased relative to 21-30 year old drivers (i.e., odds ratios $=0.87$ and 0.57 , respectively) but increased in Altoona (i.e., odds ratio $=1.38$ ). These changes are consistent with the hypothesized impact of the intervention -- SVN crashes among 16-20 year old drivers decreased in the intervention communities but increased in the control community. However, none of these changes was statistically significant.

- Discussion. It was expected that the implementation of the MinorChecker ${ }^{\circledR}$ units throughout the city of York and the introduction of an awareness campaign on underage drinking in York and Williamsport would reduce the availability of alcohol to young people which would, in turn, have an impact on the number of alcoholinvolved motor vehicle collisions among the affected age group (i.e., ages 16-20) in these communities. The reductions in SVN crashes among 16-20 year old drivers in the intervention communities (although not statistically significant) were consistent with this hypothesis.

Although encouraging, these reductions in crashes cannot be unambiguously attributed to the implementation of the MinorChecker ${ }^{*}$ program. In fact, the magnitude of the decrease in SVN crashes in Williamsport was larger than that in York. Given that licensees in Williamsport did not have the card reader units and only the awareness program was implemented, the subsequent reduction in SVN crashes would be more appropriately attributed to the awareness program and not necessarily the card readers. In light of the evidence from the compliance check and the charge data, which were not consistent with an impact on alcohol availability to young people, it cannot be stated conclusively that the implementation of the MinorChecker ${ }^{\circledR}$ program had a systematic impact on alcohol-involved road crashes among the target age group. 
Table 3

Comparison of SVN to non-SVN crashes according to age group and community

\begin{tabular}{|c|c|c|c|c|c|c|c|}
\hline & \multicolumn{3}{|r|}{ YORK } & \\
\hline & \multirow[b]{2}{*}{ non SNV } & \multirow[b]{2}{*}{ SVN } & \multirow{2}{*}{$\begin{array}{c}\text { Ratio } \\
\text { SNV/nonSNV }\end{array}$} & \multirow[t]{2}{*}{ Odds-Ratio } & \multirow[t]{2}{*}{ Std. Error } & \multicolumn{2}{|c|}{$95 \%$ Conf. Interval } \\
\hline & & & & & & LL & UL \\
\hline Before - Age 16-20 & $198(0.79)$ & $54(0.21)$ & 0.27 & & & & \\
\hline After - Age 16-20 & $241(0.81)$ & $55(0.19)$ & 0.23 & 0.84 & 0.21 & 0.55 & 1.27 \\
\hline Before - Age 21-30 & $385(0.84)$ & $72(0.16)$ & 0.19 & & & & \\
\hline \multirow[t]{5}{*}{ After - Age 21-30 } & $428(0.85)$ & $77(0.15)$ & 0.18 & 0.96 & 0.18 & 0.68 & 1.36 \\
\hline & & & Ratio of Odds-ratios & 0.87 & 0.28 & 0.50 & 1.50 \\
\hline & \multicolumn{3}{|c|}{ WILLIAMSPORT } & \multirow{3}{*}{$\begin{array}{c}\text { Odds-Ratio } \\
\text { vs. Reference }\end{array}$} & & & \\
\hline & & & Ratio & & Std. Error & \multicolumn{2}{|c|}{$95 \%$ Conf. Interval } \\
\hline & non SNV & SVN & SNV/nonSNV & & & LLL & UL \\
\hline Before - Age 16-20 & $166(0.84)$ & $32(0.16)$ & 0.19 & - & & & \\
\hline After - Age $16-20$ & $221(0.89)$ & $28(0.11)$ & 0.13 & 0.66 & 0.28 & 0.38 & 1.13 \\
\hline Before - Age 21-30 & $216(0.86)$ & $36(0.14)$ & 0.17 & & & & \\
\hline \multirow[t]{5}{*}{ After - Age 21-30 } & $227(0.84)$ & $44(0.16)$ & 0.19 & 1.16 & 0.24 & 0.72 & 1.88 \\
\hline & & & Ratio of Odds-ratios & 0.57 & 0.37 & 0.27 & 1.17 \\
\hline & \multicolumn{3}{|r|}{ ALTOONA } & & & & \\
\hline & & & Ratio & Odds-Ratio & Std. Error & \multicolumn{2}{|c|}{$95 \%$ Conf. Interva } \\
\hline & non SNV & SVN & SNV/nonSNV & vs. Reference & of $O R$ & $\mathbf{L L}$ & UL \\
\hline Before - Age 16-20 & $387(0.83)$ & $82(0.17)$ & 0.21 & & & & \\
\hline After - Age 16-20 & $394(0.82)$ & $88(0.18)$ & 0.22 & 1.05 & 0.17 & 0.76 & 1.47 \\
\hline Before - Age 21-30 & $480(0.83)$ & $96(0.17)$ & 0.20 & & & & \\
\hline \multirow[t]{2}{*}{ After - Age 21-30 } & $503(0.87)$ & $77(0.13)$ & 0.15 & 0.77 & 0.17 & 0.55 & 1.06 \\
\hline & & & Ratio of Odds-ratios & 1.38 & 0.24 & 0.87 & 2.19 \\
\hline
\end{tabular}




\subsection{DISCUSSION AND CONCLUSIONS}

The MinorChecker ${ }^{\oplus}$ represents a use of smart card technology specifically developed and implemented as a means to help reduce sales of alcohol to minors. It was intended as a tool for licensed providers of alcohol to help ensure that they sold alcohol only to those who were of legal age to purchase, possess and/or consume alcohol. As such, it presents yet another barrier between youth and alcohol, the purpose of which is to reduce the availability of alcohol to those who are not of legal age to purchase, possess or consume alcohol.

To a large extent, the onus of compliance with minimum drinking age laws has been placed on licensed alcohol retailers. Licensees and their employees bear the burden of requesting and checking the ID of potential customers who may be underage. Although it has been well-documented that some alcohol retailers appear recalcitrant in upholding their duty to request ID from youthful-looking customers, it is equally apparent that the process of checking ID can be challenging for even the most conscientious licensees. To assist licensees in their efforts, they require training and state-of-the-art tools. Electronic card reader systems, such as the MinorChecker ${ }^{\circledast}$, are examples of tools that can enhance the ability of licensees to perform their obligations easily, efficiently and effectively.

The licensees who received a MinorChecker ${ }^{\circledast}$ unit as part of this study were divided in terms of their opinions of the device. One group was very enthusiastic about it. They used it regularly and often, and extolled its virtues. The other group was highly skeptical about the value of the device. It was perceived as expensive and unreliable. Many preferred to rely on their own abilities to identify underage customers and altered or counterfeit IDs.

Card reader systems do not eliminate the need to check the ID presented manually. Young people participating in the focus groups indicated that using a borrowed license or an old, expired license from a sibling was a common means to purchase alcohol. Records downloaded from the MinorChecker ${ }^{\otimes}$ units revealed just over $1 \%$ of all licenses scanned had expired. Although some of these may represent legitimate licenses that had not been renewed, licensees should be reluctant to accept an expired license as proof of age.

The MinorChecker ${ }^{\circledast}$ records revealed relatively few underage persons attempting to purchase alcohol. It might have been expected that the card reader system would have detected large numbers of minors. In fact, it is somewhat surprising that so many customers actually presented ID that proved they were underage. It can be hypothesized that some minors might present their driver's license as ID believing (or 
hoping) that it would not be checked thoroughly. Alternatively, some might have attempted to alter the information on the front of the license only to have the MinorChecker ${ }^{\circledast}$ reveal their true age by reading the information on the magnetic stripe. In either case, to the extent that the presence of the MinorChecker ${ }^{\circledR}$ served to facilitate the checking of the ID, it proved its worth.

It was hypothesized that the implementation of the MinorChecker ${ }^{\circledR}$ units in York and the awareness program in York and Williamsport would reduce the availability of alcohol to those under 21 years of age by increasing the frequency and efficiency of licensees requesting ID from young-looking patrons. In fact, the data suggest that just the opposite occurred. The young people hired to attempt to purchase alcohol for the compliance check were asked for ID less frequently following the implementation of the awareness program and card reader units. Although a variety of hypotheses can be advanced to account for this finding, none is particularly compelling. The fact that the magnitude of the change was about the same in all three communities suggests that some unknown factor was operating at a general level to increase vigilance among licensees throughout the region (or state) at about the time the first compliance check was being conducted.

Charges for underage purchase, possession and consumption of alcohol as well as drinking-driving offenses increased following the implementation of the MinorChecker ${ }^{\circledR}$ units. Although it is interesting to speculate about the possibility that the increase in charges was related to the apparent decrease in the frequency with which licensees requested ID from young patrons over a similar period of time, it is also likely that greater enforcement accounted for the increase in charges.

The traffic crash data revealed changes consistent with the hypothesis - i.e., decreases in alcohol-involved crashes in the intervention communities and no change in the control community. None of the changes, however, was statistically significant. Although encouraging, in light of the findings from the compliance check and the charge data, it is difficult to attribute the changes in alcohol-involved road crashes unambiguously to the implementation of the MinorChecker ${ }^{\circledast}$ program in York.

The causal chain between the intervention and a reduction in traffic crashes has many links, including reduced availability and reduced consumption among the affected age group. The compliance check data would suggest that the implementation of the MinorChecker ${ }^{\circledR}$ units did not necessarily reduce the availability of alcohol to young people. In fact, following the implementation of the card readers, the hired patrons were able to purchase alcohol more frequently without being asked for ID. Although there are various interpretations that might be applied to the charge data, they are not indicative of either reduced availability or reduced consumption of alcohol among youth.

Consequently, it is not possible to state conclusively that the reduction in SVN crashes 
among 16-20 year olds in the intervention communities was a result of the implementation of the MinorChecker ${ }^{\circledast}$ unit and the associated awareness campaign.

The absence of conclusive evidence of a positive impact of the implementation of the MinorChecker ${ }^{\circledast}$ units should not detract from the apparent beneficial effects of the technology. The resounding endorsement of the device by many licensees attests to its value. The approach obviously has a role to play in the overall strategy to reduce the availability of alcohol to minors.

The card reader system is not a complete solution to the problem of underage drinking. Providing licensees with the means to check IDs quickly and easily serves to create another barrier between youth and alcohol. If used appropriately and consistently, this system can reduce the availability of alcohol to minors.

The barrier created by the card reader system is not insurmountable. Youth employ a variety of tactics to obtain alcohol. The card reader system helps remove one means of obtaining alcohol -i.e., direct purchase of alcohol by minors. Alcohol purchased by others - friends, siblings and parents - remains one of the most common sources of alcohol for youth. In this context, it is unknown the extent to which the card reader system effectively served to decrease overall availability of alcohol to youth or merely prompted youth to turn to other means of obtaining alcohol. If the latter, then in the absence of other complementary strategies to reduce the availability of alcohol to youth, we should not expect to see an impact on alcohol-related problems among those under 21 years of age.

The major limitation of the card reader system is not the technology but the user of the technology. The devices do what they were designed to do. But if the user lacks the desire or commitment to use the device consistently, it cannot fulfill its intended purpose. To be effective it must be used as part of a program to check the identification of every customer who appears under 30 years of age. This requires a strong policy and commitment by the management of the establishment. Periodic enforcement or "compliance checks" conducted by an outside agency would reinforce the policy and provide motivation for adherence.

- Further research. In retrospect, implementing the card reader system on a wide-scale basis throughout an entire community might have been too diffuse an effort to produce substantial and measurable reductions in the overall availability of alcohol to young people. Without a substantial change in the availability of alcohol to young people, it is unlikely that the card reader program would have had an impact on alcohol-related problems among young people in the community. The card reader system also only addressed one source of alcohol -- i.e., direct purchases by young people. Although the awareness program addressed underage drinking in general, no 
attempt was made to intervene with other sources of alcohol for young people -- e.g., alcohol obtained from others or from parents.

In addition, no attempt was made to include an enforcement component in the intervention. This was, in fact, a conscious decision to isolate the focus on the card reader system and not to confound the issue with the potentially powerful effects that are sometimes associated with intensive enforcement activities.

The value of the card reader system may be best demonstrated as part of a more comprehensive program to reduce the availability of alcohol to underage youth. Such a program would include the universal implementation of the card readers in a well-defined and geographically limited community, an awareness and educational program for servers/licensees, an awareness program for youth, as well as enhanced enforcement activities targeted at both youth and licensees. Confining the program to a small community or limited geographic area (such as in and around a college campus) would allow greater control and facilitate targeting of activities. 


\section{Acknowledgements}

The authors would like to thank the following people for their contributions to this project.

Charles Bacas (MCS Marketing)

Fred Zimmerman (CommStar Inc.)

Donna Hawkins (Pennsylvania Liquor Control Board)

Jacqueline Spaid (Pennsylvania Liquor Control Board)

Warren Ashburn (Kelly Michener Inc.)

Melinda Schmidt

Chris Still

Craig Hockenbury

Don Good

Elizabeth Hawkins

Heather Hawkins

Marcie Rushinskie

Shawn Donovan

We also extend our gratitude to the numerous licensees in York who participated in the MinorChecker ${ }^{\circledast}$ program and tolerated our frequent intrusions to download data. 


\section{REFERENCES}

A Generation at Risk: Alcohol, Tobacco, Other Drugs, Weapons, Violence, and Pennsylvania's Youth: The 1997 Sunvey. Diagnostics Plus, State College, Pennsylvania.

Douglass, R.L. and Filkins, L.D. 1974. Empirical development of a surrogate measure of alcohol involvement in official accident data. HIT LAB Reports 4(9): 7-12

DuMouchel, W. Williams, A.F. and Zador, P. 1986. Raising the alcohol purchase age: Its effects on fatal motor vehicle crashes in 26 states. Washington, DC.: Insurance Institute for Highway Safety.

Fell, J.C. 1988. Effectiveness of Raising the Drinking Age to 21. 14th International Forum on Traffic Records Systems, July 18-28, 1988, San Diego, California.

George, W.H., Crowe, L.C., Abwener, D., \& Skinner, J.B. 1989. Effects of raising the drinking age to 21 years in New York state on self-reported consumption by college students . Journal of Applied Social Psychology, 19(8): 623-635.

Hoxie, P. and Skinner, D. 1985. A Statistical Analysis of the Effects of a Uniform Minimum Drinking Age. National Highway Traffic Safety Report no.

FR-45-U-NHT-86-08. Cambridge, MA.: U.S. Department of Transportation.

Johnson, V. \& White H.R. 1989. An investigation of factors related to intoxicated driving behaviours among youth. Journal of Studies on Alcohol, 50(4): 320-330.

Kusserow, R.P. 1991a. Youth and Alcohol: A National Survey. Do They Know What They're Drinking? Washington, DC.: Department of Health and Human Services, Office of Inspector General.

Kusserow, R.P. 1991b. Youth and Alcohol: A National Survey. Drinking Habits, Access, Attitudes and Knowledge. Washington, DC.: Department of Health and Human Services, Office of Inspector General.

Kusserow, R.P. 1991c. Youth and Alcohol: Laws and Enforcement: Is the 21-Year-Old Drinking Age a Myth? Washington, DC.: Department of Health and Human Services, Office of Inspector General.

Lewis, N.O., Lapham, S.C. \& Skipper, B.J. 1998. Drive-up liquor windows and convicted drunk drivers: A comparative analysis of place of purchase. Accident Analysis and Prevention, 30(6): 763-772.

National Highway Traffic Safety Administration. 1999. Traffic Safety Facts 1998. DOT HS 808983 . Washington, DC: U.S. Department of Transportation, National Highway Traffic Safety Administration. October.

O'Malley, P.M., Johnston, L.D., \& Bachman, J.G. 1998. Alcohol use among adolescents . Alcohol Health and Research World, 22(2): 85-93. 
Peters, J. 1997. Is age the issue? Prevention File, 12(2): 7-10.

Preusser, D.F. and Williams, A.F. 1992. Sales of alcohol to underage purchasers in three New York counties and Washington, D.C. Journal of Public Health Policy, 13(3): 306-317.

Preusser, D.F. Ulmer, R.G. and Preusser, C.W. 1993. Enforcement of Underage Impaired-Driving Laws. DOT HS 807920 . Washington, DC.: Insurance Institute for Highway Safety.

Preusser, D.F. Ulmer, R.G. and Preusser, C.W. 1992. Obstacles to Enforcement of Youthful (Under 21) Impaired Driving. DOT HS 807 878. Washington, DC.: National Highway Traffic Safety Administration. February.

Preusser, D.F. Ferguson, S.A. Williams, A.F. and Farmer, C.M. 1995. Underage Access to Alcohol: Sources of Alcohol and Use of False Identification. Arlington, VA: Insurance Institute for Highway Safety.

Preusser, D.F. Williams A.F., and Weinstein, H.B. 1994. Policing underage alcohol sales . Journal of Safety Research, 25(3): 127-133.

Schulenberg, J., O'Malley, P.M., Bachman, J.G., Wadsworth, K.N. \& Johnston, L.D. 1996. Getting drunk and growing up: Trajectories of frequent binge drinking during the transition to young adulthood. Journal of Studies on Alcohol, 57(3): 289-304.

Smart, R.G., Adlaf, E.M. \& Walsh, G.W. 1996. Procurement of alcohol and underage drinking among adolescents in Ontario. Journal of Studies on Alcohol, 57(4): 419-424.

Sweedler, B.M. 1988. What happens when the drinking age is raised? Paper presented at the Alberta Alcohol and Drug Abuse Commission's Institute on Bridging the Gaps: Law Enforcement-Communities-Helping Agencies, July 4, 1988, Calgary, Alberta.

Sweedler, B.M. and Moulden, J.V. 1986. Does raising the drinking age reduce traffic accidents? The United States experience. Paper presented at the International Symposium on Young Drivers' Alcohol- and Drug-Impairment. Washington, DC.: U.S. Department of Transportation.

Toomey, T.L., Rosenfeld C., \& Wagenaar, A.C. 1996. The minimum legal drinking age: History, effectiveness, and ongoing debate. Alcohol Health and Research World, 20(4): 213-218.

United States General Accounting Office. 1987. Drinking Age Laws: An Evaluation Synthesis of Their Impact on Highway Safety. Report to the Chairman, Subcommittee on Investigations and Oversight, Committee on Public Works and Transportation, House of Representatives. Washington, DC.: U.S. United States General Accounting Office.

Wagenaar, A.C. and Wolfson, M. 1994. Enforcement of the legal minimum drinking age in the United States. Journal of Public Health Policy, 15(1): 37-53. 
Wagenaar, A.C. and Wolfson, M. 1995. Deterring sales and provision of alcohol to minors. Public Health Reports.

Wagenaar, A.C., Toomey, T.L., Murray, D.M., Short, B.J., Wolfson, M., and JonesWebb, R. 1996. Sources of Alcohol for underage Drinkers . Journal of Studies on Alcohol, 57(3): 325-333.

Wolfson M., Toomey T.L., Forster J.L., Wagenaar A.C., McGovern P.G. \& Perry C.L. 1996. Characteristics, policies and practices of alcohol outlets and sales to underage persons . Journal of Studies on Alcohol, 57(6): 670-674. 


\section{Appendix A}

\section{Declaration of Age Form (PLCB-931)}




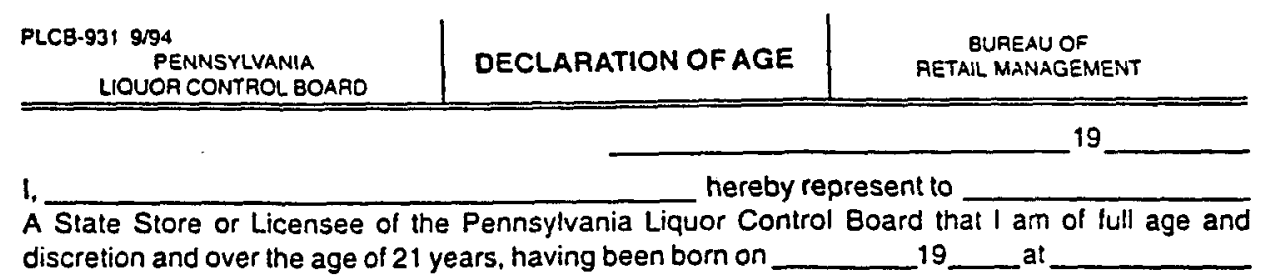
discretion and over the age of 21 years, having been born on __ alcoholic beverages to the undersigned.

Serial Number ol Identification Card

I UNDERSTAND THAT I AM SUEJECT TO A FINE OF $\$ 300$ AND 60 DAYS IMPRISONMENT FOA ANY MISAEPRESENTATION HEREIN. I FURTHER UNDEASTAND THAT I AM SUBJECT TO LOSS OF DAIVING PAIVILEGES. FINES ANO PENALTIES OF UP TO SSOO AND POSSIBLE IMPRISONMENT FOR UP TO ONE (1) YEAR FOR ANY MISAEPRESENTATION HEREIN. WITNESS:

NAME

SIGNATURE

ADORESS

ADDRESS

(Person Requesing Service)

The PLCB reserves the right to furnish the Declaration of Age card to any appropriate la:s entorcement agency.

\begin{tabular}{l} 
Identification Shown \\
\hline Signature Compared \\
\hline Race \\
Complexion \\
Hair Color \\
Weight \\
Height \\
Code Requested \\
Time___ Sex \\
Reason Relused \\
\hline
\end{tabular}


DOT HS 809321

July 2001 